\title{
Harnessing Photoelectrochemistry for Wastewater Nitrate Treatment Coupled with Resource Recovery
}

\author{
Luisa Barrera $^{1}$ and Rohini Bala Chandran ${ }^{1 *}$
}

\begin{abstract}
Wastewater is a misplaced resource well suited to recover nutrients, value-added chemicals, energy, and clean water. A photoelectrochemical device is proposed to transform wastewater nitrates to ammonia and nitrous oxide, coupled with water oxidation. Numerical models were developed to quantify the dependence of process efficiencies and nitrogen-removal rates on light absorber band gaps, electrocatalytic kinetic parameters, competing oxygen reduction and hydrogen evolution reactions, and the reacting nitrate species concentrations that affect the mass-transfer limited current densities. With a single light-absorber and state-of-the-art catalysts, optimal solar-to-chemical efficiencies of $7 \%$ and $10 \%$ and nitrogen-removal rates of 260 and $395 \mathrm{gN} \mathrm{m}^{-2}$ day $^{-1}$ are predicted for nitrate reduction to ammonia and nitrous oxide respectively. The influence of competing reactions on the performance depends on the nitrate concentration and band gap of the light absorber modeled. Oxygen reduction is more dominant than hydrogen evolution to compete with the nitrate reduction reaction, but is mass-transfer limited. Even with kinetic parameters that enhanced the driving forces for the competing reactions, the performance is only minimally affected by these reactions for optimally selected band gaps and nitrate concentrations larger than $100 \mathrm{mM}$. Theoretically predicted peak nitrogen removal rates and specific energy intensities are competitive with reported estimates for bioelectrochemical and Sharon-Anammox processes for ammonia recovery and nitrogen removal respectively. This result, together with the added benefit of harnessing sunlight to produce value-added products, indicates promise in the photoelectrochemical approach as a tertiary pathway to recover nutrients and energy from wastewater nitrates.
\end{abstract}

\section{TOC Graphic}
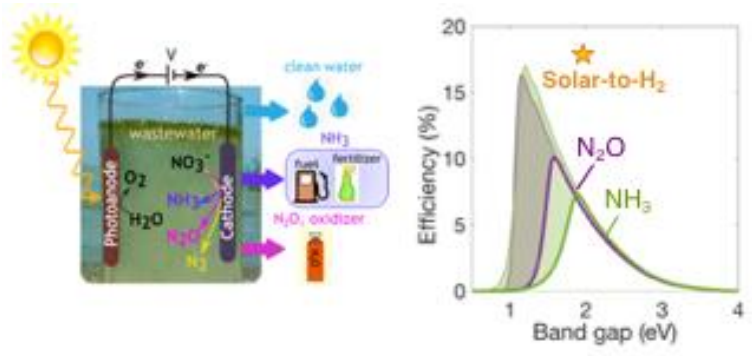

\footnotetext{
${ }^{1}$ Department of Mechanical Engineering, 2350 Hayward St., G. G. Brown Building, University of Michigan, Ann Arbor, MI 48109

*Corresponding author: rbchan@umich.edu
} 


\section{1. Introduction}

Excessive anthropogenic production of nitrogen fertilizers combined with fossil-fuel

3 combustion has significantly disrupted the natural nitrogen cycle ${ }^{1-3}$, leading to the contamination

4 of groundwater and other surface-water bodies with various reactive forms of nitrogen—nitrates

$5\left(\mathrm{NO}_{3}^{-}\right)$, nitrites $\left(\mathrm{NO}_{2}{ }^{-}\right)$, ammonia $\left(\mathrm{NH}_{3}\right)$, ammonium $\left(\mathrm{NH}_{4}^{+}\right)$and organic nitrogen. These

6 contaminants result in environmental threats such as algal blooms, suffocation of aquatic wildlife,

7 and health risks in humans, e.g. excessive amounts of nitrates in drinking water causes

8 methemoglobinemia ("blue baby" syndrome) $)^{4-8}$. While several strategies have been reported to

9 recover value-added products - energy from biogas and chemicals including biopolymers, bio-

10 oils, and biochar from organic contaminants - far less emphasis has been placed on nutrient (i.e.

11 nitrogen) and energy recovery from nitrogen contaminants ${ }^{9-12}$.

12 This study focuses on evaluating the feasibility of a photoelectrochemical approach to

13 recover nitrogen nutrients from $\mathrm{NO}_{3}{ }^{-}$contaminants present in ion-exchange brines ${ }^{13-16}$ and treated

14 wastewater ${ }^{11,17-19}$. Biological nitrification-denitrification treatment processes are attractive as they

15 utilize microbes to consume and remove the excess nutrients ${ }^{20,21}$. However, these processes are

16 energy intensive ${ }^{22}$, not effective in effluent streams that harbor conditions unsuitable for microbial

17 growth $^{3,23}$, and have not been optimized for resource recovery ${ }^{12}$. Ion-exchange ${ }^{5,24,25}$,

18 electrodialysis ${ }^{26,27}$, and reverse osmosis $^{28,29}$ are used to treat nitrates (and other ions) at an

19 industrial scale for drinking water applications, but result in the production of a secondary nitrate-

20 concentrated brine that requires further treatment ${ }^{30}$. Hence, there is an increasing demand to

21 develop wastewater treatment technologies to harness renewable energy, to be effective for a wide

22 range of effluent stream conditions and to facilitate resource recovery in the form of nutrients and

23 energy. To meet these critical needs, photoelectrochemical devices offer the potential to couple 
1 sunlight with electron-transfer reactions to treat and transform nitrogen-contaminants to value-

2 added chemicals and therefore facilitate nitrogen recovery.

3 Prior work has provided theoretical limits for the solar-to-fuel energy conversion

4 efficiencies and established guidelines to select semiconductor and co-catalysts/electrocatalysts to

5 optimize the efficiency for photoelectrochemical water splitting devices, which generate hydrogen

6 and oxygen from water using light absorbers and electrocatalysts ${ }^{31-42}$. However, the same extent

7 of understanding is not available for photoelectrochemical nitrate treatment devices. Photocatalytic

8 nitrate reduction has been investigated predominantly with $\mathrm{TiO}_{2}$-based light absorbers with $\mathrm{NO}_{3}{ }^{-}$

9 reduction often paired with sacrificial hole-scavengers (methanol, oxalic acid, and formic acid) ${ }^{43-}$

$10{ }^{46}$. However, $\mathrm{TiO}_{2}$ limits process efficiencies due to the low sunlight absorption and the presence

11 of hole-scavengers lead to toxicity concerns for water treatment applications. Comprehensive

12 reviews have been reported on electrochemical denitrification, i.e. $\mathrm{NO}_{3}^{-}$to $\mathrm{N}_{2}$ conversion,

13 including investigations on metallic and bimetallic electrocatalysts for $\mathrm{NO}_{3}{ }^{-}$to $\mathrm{N}_{2}$ and $\mathrm{NH}_{3}$

14 conversion, and studies that probe fundamental reaction mechanisms ${ }^{47-60}$. However, the focus in a

15 majority of these studies has been on electrocatalytically reducing $\mathrm{NO}_{3}{ }^{-}$to $\mathrm{N}_{2}$, which poses

16 formidable kinetic (reactivity and selectivity) challenges. Therefore, there is a lack of knowledge

17 on the ideal performance limits and the impacts of materials parameters on the performance of a

18 photoelectrochemical approach to recover nitrogen nutrients from wastewater.

19 The objective of this study is to theoretically predict the solar-to-chemical energy

20 conversion efficiencies and the rate of recovery of nitrogen for a photoelectrochemical device that

21 is operating on treated wastewater with predominantly nitrate contaminants (Figure 1). A notable

22 innovation introduced in the modeling approach developed is the capability to account for the

23 effects of competing hydrogen evolution and the oxygen reduction reactions that can compete with 
1 the desired nitrate reduction reaction at the cathode, within a simplified, yet powerful, equivalent

2 circuit modeling framework. The model developed is used to obtain the impacts of material

3 parameters, including the light-absorber band gaps, electrocatalyst exchange current densities and

4 charge-transfer coefficients for the desired and the competing reactions, and operating nitrate

5 concentration in the waste stream, on all the performance metrics. These results are interpreted to

6 provide guidelines to select materials for the light absorbers and electrocatalysts to maximize

7 resource (nitrogen) recovery. Furthermore, the predicted performance metrics are used to compare

8 the proposed approach with the state-of-the-art nitrogen removal/recovery technologies - the

9 Sharon-Annamox process ${ }^{61,62}$ and ammonia stripping using electrochemical flow reactors ${ }^{63}$.

\section{2. Photoelectrochemical Device for Wastewater Nitrate Treatment}

In this work, we propose a photoelectrochemical device to pair water oxidation with nitrate

12 reduction (Figure 1). A photoactive semiconductor anode absorbs incident sunlight and is

13 electrically connected to the cathode. The holes generated at the photoanode surface effect the

14 oxygen evolution reaction (OER) while at the cathode surface the electrons effect the nitrate

15 reduction reaction (NO3RR) to the desired products including $\mathrm{NH}_{3} / \mathrm{NH}_{4}{ }^{+}$and $\mathrm{N}_{2} \mathrm{O}$. An ion-

16 exchange membrane may be present to facilitate ion transport while preventing gas crossover

17 between the electrodes. Compared to the removal of $\mathrm{NO}_{3}{ }^{-}$contaminants as $\mathrm{N}_{2}$, the transformation

18 to $\mathrm{NH}_{3} / \mathrm{NH}_{4}{ }^{+}$and $\mathrm{N}_{2} \mathrm{O}$ recovers the $\mathrm{N}$-nutrients and upgrades the energetic value of the reactive-

19 nitrogen contaminant species. Aqueous $\mathrm{NH}_{3} / \mathrm{NH}_{4}{ }^{+}$can be reused as a fertilizer and/or oxidized to

20 generate electricity in an ammonia fuel-cell, and gaseous $\mathrm{NH}_{3}$ can be used as a fuel to generate

21 heat and produce electricity ${ }^{64-66}$. Despite being a potent greenhouse gas, $\mathrm{N}_{2} \mathrm{O}$ is also a powerful

22 oxidizer, especially for the combustion of rocket-fuel and biogas and for supercharging

23 applications ${ }^{67,68}$. It increases the energy released during the combustion of $\mathrm{CH}_{4}$ by $37 \%$ as 


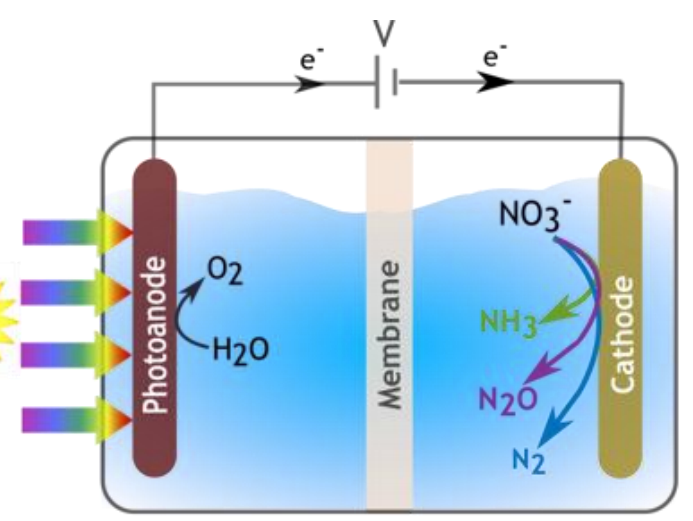

\begin{tabular}{|c|c|c|c|}
\hline \multicolumn{2}{|l|}{ Oxidation } & \multicolumn{2}{|l|}{ Reduction } \\
\hline $2 \mathrm{OH}^{-} \rightarrow 1 / 2 \mathrm{O}_{2}(\mathrm{~g})+\mathrm{H}_{2} \mathrm{O}+2 \mathrm{e}^{-}$ & $E^{0}=1.23 \mathrm{~V}$ & $\mathrm{NO}_{3}^{-}+7 \mathrm{H}_{2} \mathrm{O}+8 \mathrm{e}^{-} \rightarrow \mathrm{NH}_{3}(\mathrm{~g})+9 \mathrm{OH}^{-}$ & $E^{0}=0.82 \mathrm{~V}$ \\
\hline Net Reaction, R1: & \multicolumn{2}{|c|}{$\mathrm{NO}_{3}^{-}+3 \mathrm{H}_{2} \mathrm{O} \rightarrow \mathrm{NH}_{3}(\mathrm{~g})+\mathrm{OH}^{-}+2 \mathrm{O}_{2}(\mathrm{~g})$} & $E_{\mathrm{R} 1}^{0}=-0.41 \mathrm{~V}$ \\
\hline $2 \mathrm{OH}^{-} \rightarrow 1 / 2 \mathrm{O}_{2}(\mathrm{~g})+\mathrm{H}_{2} \mathrm{O}+2 \mathrm{e}^{-}$ & $E^{0}=1.23 \mathrm{~V}$ & $2 \mathrm{NO}_{3}^{-}+5 \mathrm{H}_{2} \mathrm{O}+8 \mathrm{e}^{-} \rightarrow \mathrm{N}_{2} \mathrm{O}(\mathrm{g})+10 \mathrm{OH}^{-}$ & $E^{0}=1.12 \mathrm{~V}$ \\
\hline Net Reaction, R2: & \multicolumn{2}{|c|}{$2 \mathrm{NO}_{3}^{-}+\mathrm{H}_{2} \mathrm{O} \rightarrow \mathrm{N}_{2} \mathrm{O}(\mathrm{g})+2 \mathrm{OH}^{-}+2 \mathrm{O}_{2}(\mathrm{~g})$} & $E_{\mathrm{R} 2}^{0}=-0.11 \mathrm{~V}$ \\
\hline $2 \mathrm{OH}^{-} \rightarrow 1 / 2 \mathrm{O}_{2}(\mathrm{~g})+\mathrm{H}_{2} \mathrm{O}+2 \mathrm{e}^{-}$ & $E^{0}=1.23 \mathrm{~V}$ & $2 \mathrm{NO}_{3}^{-}+6 \mathrm{H}_{2} \mathrm{O}+10 \mathrm{e}^{-} \rightarrow \mathrm{N}_{2}(\mathrm{~g})+12 \mathrm{OH}^{-}$ & $E^{0}=1.25 \mathrm{~V}$ \\
\hline Net Reaction, R3: & \multicolumn{2}{|c|}{$2 \mathrm{NO}_{3}^{-}+\mathrm{H}_{2} \mathrm{O} \rightarrow \mathrm{N}_{2}(\mathrm{~g})+2 \mathrm{OH}^{-}+5 / 2 \mathrm{O}_{2}(\mathrm{~g})$} & $E_{\mathrm{R} 3}^{0}=0.02 \mathrm{~V}$ \\
\hline
\end{tabular}

Figure 1: Schematic of a photoelectrochemical device for treating wastewater nitrate contaminants. Selective water oxidation at the photoanode and the $\mathrm{NO}_{3}{ }^{-}$reduction pathways to form $\mathrm{NH}_{3}(\mathrm{R} 1), \mathrm{N}_{2} \mathrm{O}(\mathrm{R} 2)$ and $\mathrm{N}_{2}(\mathrm{R} 3)$ are depicted. All the standard potentials, $E^{0}$, for aqueous solutions at $25^{\circ} \mathrm{C}$ are reported vs. NHE based on a $1 \mathrm{~atm}$ standard state for $\mathrm{H}_{2}$. Unless otherwise mentioned all species are in the aqueous phase ${ }^{69,70}$. A negative $E^{0}$ for a net reaction indicates that it is thermodynamically uphill, while a positive $E^{0}$ indicates reaction spontaneity.

1 compared to using $\mathrm{O}_{2}$ as an oxidizer, and therefore has been previously considered as a viable end-

2 product for energy recovery ${ }^{67,71}$.

3 As an idealized starting point for our analyses, we assumed the presence of predominantly

$4 \mathrm{NO}_{3}^{-}$contaminants in the waste stream. Such an assumption could be reasonable for a tertiary

5 treatment process designed for resource recovery from nitrogen-contaminants in pre-treated

6 wastewater from municipal wastewater treatment plants, ion-exchange brines and other industrial

7 processes $^{11,13-19}$. 
branches; the overall operating potential of the diode is given by Eq. (2).

$$
\begin{gathered}
V_{\text {anode }}=E_{\text {eq,OER }}+\eta_{\mathrm{OER}} \\
V_{\text {cathode }}=\left\{\begin{array}{c}
E_{\text {eq,NO3RR }}+\eta_{\mathrm{NO} 3 \mathrm{RR}} \\
E_{\text {eq,HER }}+\eta_{\mathrm{HER}} \\
E_{\text {eq,ORR }}+\eta_{\mathrm{ORR}}
\end{array}\right. \\
V_{\mathrm{op}}=V_{\text {anode }}-V_{\text {cathode }}
\end{gathered}
$$

11 At the anode, selective OER is justified by the low likelihood of oxidizing nitrogen-products $\left(\mathrm{N}_{2} \mathrm{O}\right.$ 12 and $\mathrm{NH}_{3}$ especially for $\mathrm{pH}>12^{23,72}$ ). However, at the cathode, in addition to the desired nitrate 13 reduction reaction (NO3RR), competing hydrogen evolution (HER) and oxygen reduction (ORR)

14 reactions were also modeled. The HER has been reported to compete with the NO3RR in prior 15 work with $\mathrm{Cu}$ catalysts $3,57,72$; the $\mathrm{ORR}$ was considered due to the $\mathrm{O}_{2}$ produced at the anode, which 16 can crossover and react at the cathode surface.

17 The Nernstian potential, $E_{\text {eq }}$, was included (Eq. (3)) as the minimum electrical load at the 18 cathode and the anode. 


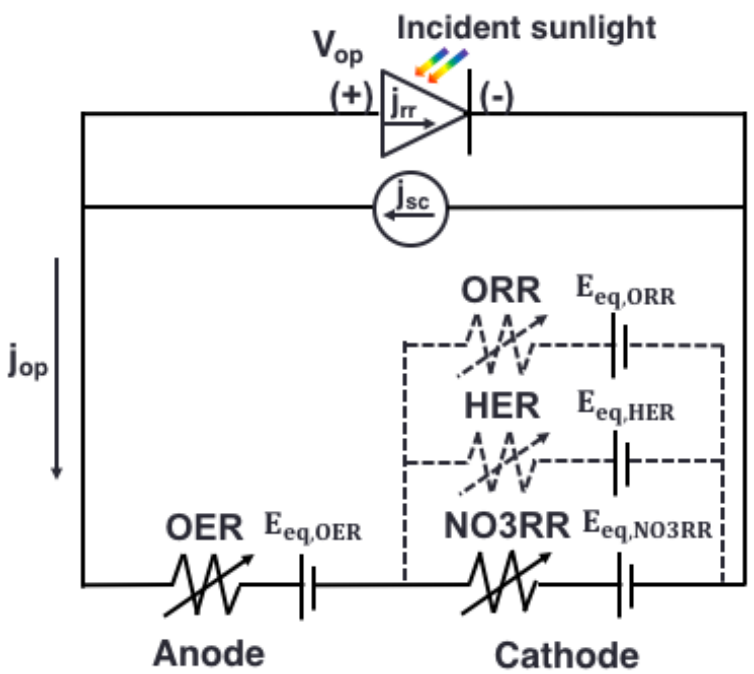

Figure 2: Equivalent circuit diagram to model the operation and performance of the photoelectrochemical device in Figure 1. The semiconductor light-absorber was modeled as a photodiode and the electrochemical reactions as variable resistors with minimum electrical loads corresponding to the thermodynamic potentials for the corresponding reactions. Selective oxygen evolution reaction (OER) at the anode and parallel reactions were modeled at the cathode including the desired NO3RR, and the competing HER and ORR. Desired reactions in the circuit are indicated by the solid lines and the undesired and competing reactions at the cathode are indicated by the dashed lines.

Current conservation, Eq. (4), was satisfied in the circuit, while taking into account the parallel

11 and competing reactions occurring at the cathode. The sign convention adopted implements the

12 reduction current densities to be negative and the oxidation current density to be positive.

$$
j_{\mathrm{op}}=j_{\mathrm{OER}}=-\sum_{i=\mathrm{NO} 3 \mathrm{RR}, \mathrm{ORR}, \mathrm{HER}} j_{i}
$$

13 Light Absorber: The semiconductor light absorber was modeled as a diode with the pertinent

14 governing equations and key assumptions summarized in Table $1^{31-38}$. Ideal diode behavior with

15 only radiative recombination (Eqs. (5)-(7)) and a large optical path length was assumed to keep

16 the analyses general and to analyze a wide range of light absorber bandgaps. However, the trends

17 predicted for the impacts of the material band gaps on the performance metrics are expected to be

18 valid even with more realistic recombination models. 
1 Table 1: List of the governing equations for the semiconductor light absorber in the equivalent

2 circuit (0-D) model

\begin{tabular}{ll}
\hline Physics modeled & Governing equations and key assumptions \\
\hline $\begin{array}{l}\text { Current-potential } \\
\text { behavior of the }\end{array}$ & Shockley-Queisser detailed-balance model $^{36}$ \\
semiconductor & $j_{\mathrm{op}}=j_{\mathrm{sc}}-j_{\mathrm{rr}}\left(e^{\frac{q_{e} V_{\mathrm{op}}}{n_{d} k_{\mathrm{B}} T}}-1\right)$
\end{tabular}

(i) Optically thick semiconductor absorbs all the above-band-gap photons to ensure that current density is not limited by the material design, i.e. planar electrodes ${ }^{36}$, photocatalytic particle suspension reactors ${ }^{33}$, nanowires ${ }^{73}$ etc.

(ii) Negligible optical losses due to reflection at the surface of the light absorber to keep the analysis generic and applicable over a wide range of material bandgaps

(iii) Ideal diode with only radiative recombination dictated by the rate of thermal emission of photon at ambient temperature, $\mathrm{T}=298.15 \mathrm{~K}$

Short-circuit current density, $j_{\mathrm{sc}}$

$$
j_{\mathrm{sc}}=q_{e} \int_{\substack{E_{g} \\ v_{\mathrm{g}}=\frac{E_{\mathrm{B}} T}{k_{\mathrm{B}} T}}}^{\infty} \phi_{\text {solar }}(v) \mathrm{d} v
$$

(i) Electron-hole $\left(\mathrm{e}^{-} / \mathrm{h}^{+}\right)$pairs are generated by each and every incident photon with energy larger than its band gap of $E_{g}$

(ii) Excited-state charge carriers rapidly thermalize to the band edges and each absorbed photon produces only one $\mathrm{e}^{-} / \mathrm{h}^{+}$pair

Radiative
current density, $j_{\mathrm{rr}}$

$$
j_{\mathrm{rr}}=2 q_{e}\left(\frac{2 \pi}{\mathrm{c}^{2}}\right) \int_{v_{\mathrm{g}}}^{\infty} \frac{v^{2}}{e^{\frac{h v}{k_{\mathrm{B}} T}}-1} \mathrm{~d} v
$$

(i) Light absorber is surrounded by a blackbody at the same temperature as that of the diode that is at $\mathrm{T}=298.15 \mathrm{~K}^{36}$ mass-transfer $\left(\eta_{i, \mathrm{mt}}\right)$ and the kinetic $\left(\eta_{i, \mathrm{k}}\right)$ overpotentials for all the redox reactions considered, i.e. $i=$ OER, NO3RR, HER, and ORR (Eqs. (8) and (9)).

$$
\eta_{i}=\eta_{i, \mathrm{k}}+\eta_{i, \mathrm{mt}}
$$

7 The mass-transfer overpotential was included to account for the bulk concentration-dependent

8 limiting current densities for all redox species $\left(\mathrm{NO}_{3}{ }^{-} / \mathrm{NO}_{2}{ }^{-}\right.$for $\mathrm{NO} 3 \mathrm{RR}, \mathrm{H}_{2} \mathrm{O} / \mathrm{H}_{2}$ for $\mathrm{HER}$, and

$9 \mathrm{O}_{2} / \mathrm{OH}$ for $\mathrm{ORR}$ ) except for the OER. For the OER, this mass-transfer overpotential component in

10 Eq. (8) is assumed to be negligibly small because of the large concentration of the reacting species,

$11 c_{\mathrm{H}_{2} \mathrm{O}}=55.5 \mathrm{M}(\mathrm{pH}=1)$ and $c_{\mathrm{OH}^{-}}=1 \mathrm{M}(\mathrm{pH}=14)$. Equation (9) accounts for the mass-transfer 12 overpotential, 


$$
\eta_{i, \mathrm{mt}}=\frac{R T}{F n_{e}} \ln \left(\frac{\left(1-\frac{j_{i}}{j_{l, i, c}}\right)^{v_{i, c}}}{\left(1-\frac{j_{i}}{j_{l, i, a}}\right)^{v_{i, a}}}\right)
$$

where, $j_{l}$ is the limiting current density for the cathodic $(c)$ and anodic $(a)$ half-reactions. Limiting

2 current densities were calculated assuming diffusion-limited species transport (Eq. (10)) of the

3 oxidized $(\mathrm{O})$ or reduced species $(\mathrm{R})$, with a concentration boundary layer thicknesses of $10 \mu \mathrm{m}$,

$4 \delta_{B L}=10 \mu \mathrm{m}$, which is a reasonable assumption for planar electrode architectures with laminar

5 flow regime ${ }^{74}$,

6

8 and irreversible cathodic reactions (Eq. (12)),

$$
\begin{gathered}
j_{i}=j_{0, \text { ref }, i}\left(\frac{C_{\mathrm{R}, \mathrm{bulk}}}{C_{\mathrm{R}, \mathrm{bulk}, \mathrm{ref}}}\right)^{\left(\nu_{\mathrm{R}} \alpha_{c, i}\right) / n_{e}}\left(\frac{C_{\mathrm{O}, \mathrm{bulk}}}{C_{\text {O,bulk,ref }}}\right)^{\left(v_{\mathrm{O}} \alpha_{a, i}\right) / n_{e}}\left(\exp \left(\frac{\alpha_{a, i} \eta_{i, \mathrm{k}}}{R T / F}\right)-\exp \left(\frac{-\alpha_{c, i} \eta_{i, \mathrm{k}}}{R T / F}\right)\right) \\
j_{i}=j_{0, \text { ref }, i}\left(\frac{C_{\text {O,bulk }}}{C_{\text {O,bulk,ref }}}\right)^{1-\alpha_{c, i} / n_{e}}\left(-\exp \left(\frac{-\alpha_{c, i} \eta_{i, \mathrm{k}}}{R T / F}\right)\right)
\end{gathered}
$$

where, $j_{0, \text { ref,i }}$ is the reference surface- and concentration-dependent exchange current density of

10 the $i^{\text {th }}$ reaction (for a selected electrocatalyst, the larger the $j_{0, i}$ value, the faster the rate is for both

11 the anodic and cathodic directions of the reversible redox reactions); $\alpha_{a}$ and $\alpha_{c}$ are the charge-

12 transfer coefficients indicating the symmetry of the activation barrier for the reaction. Equation

13 (11) was applied to model the kinetics for OER, HER, and ORR, whereas Eq. (12) was used for

14 NO3RR. A literature review was performed to identify the state-of-the-art catalysts for OER and

15 NO3RR, based on which the kinetic parameters $\left(j_{0, \mathrm{ref}, i}, \alpha_{c, i}, \alpha_{a, i}\right)$ were determined for these

16 reactions (Table 2). For NO3RR, catalysts were selected based on satisfying two criteria: (a) the

17 availability of kinetic parameters, or cyclic voltammograms or Tafel plots based on which kinetic

18 parameters can be extracted, and (b) the inclusion of product composition analyses to determine 
1 Table 2: Reactions modeled with relevant $\mathrm{pH}$, reference exchange current density, $j 0$,ref; charge 2 transfer coefficients, $\alpha_{c}$ and $\alpha_{a}$; N/A for the charge-transfer coefficients implies the use of the 3 irreversible equation form (Eq. (12)); bulk reference concentrations, cbulk,ref, extracted from the 4 literature for the catalysts are listed; $\mathrm{pH} 1$ and $\mathrm{pH} 14$ data used for $\mathrm{NH}_{3}$ and $\mathrm{N}_{2} \mathrm{O}$ production 5 respectively

\begin{tabular}{|c|c|c|c|c|c|c|}
\hline \multirow[t]{2}{*}{ Reaction } & \multirow[t]{2}{*}{ pH } & \multirow[t]{2}{*}{ Catalyst } & \multicolumn{4}{|c|}{ Kinetic Parameters for Eqs. (11) and (12) } \\
\hline & & & $j_{0, \text { ref }}\left(\mathrm{A} \mathrm{m}^{-2}\right)$ & $\alpha_{c}$ & $\alpha_{a}$ & $c_{\text {bulk,ref }}(\mathbf{m M})$ \\
\hline \multirow{2}{*}{$\mathrm{OER}^{33,41,75}$} & 1 & $\mathrm{RuO}_{2}$ & $6.68 \times 10^{-4}$ & 0.1 & 1 & $c_{\mathrm{H}^{+}}=1000 ; c_{\mathrm{O}_{2}, \mathrm{aq}}=1.3$ \\
\hline & 14 & $\mathrm{IrO}_{2}$ & 0.48 & 0.63 & 0.39 & $c_{\mathrm{OH}^{-}}=1000 ; c_{\mathrm{O}_{2}, \mathrm{aq}}=1.3$ \\
\hline \multirow{2}{*}{$\mathrm{NO} \mathrm{RR}^{57,58}$} & 1 & $\mathrm{Sn}-\mathrm{Pt}$ & $2.12 \times 10^{-3}$ & 0.54 & N/A & $c_{\mathrm{NO}_{3}^{-}}=10 ; c_{\mathrm{H}^{+}}=100$ \\
\hline & 14 & $\mathrm{Cu}$ & $1.12 \times 10^{-2}$ & 0.30 & N/A & $c_{\mathrm{NO}_{3}^{-}}=100 ; c_{\mathrm{OH}^{-}}=1000$ \\
\hline \multirow{2}{*}{ HER $^{76,77}$} & 1 & $\mathrm{Pt}$ & 10 & 05 & 05 & $c_{\mathrm{H}^{+}}=1000 ; c_{\mathrm{H}_{2}, \mathrm{aq}}=0.78$ \\
\hline & 14 & $\mathrm{rl}$ & 10 & $0 . J$ & $0 . J$ & $c_{\mathrm{OH}^{-}}=1000 ; c_{\mathrm{H}_{2}, a q}=0.78$ \\
\hline \multirow{2}{*}{$\mathrm{ORR}^{78-81}$} & 1 & $\mathrm{Pt}$ & $10^{-1}$ & 09 & 01 & $c_{\mathrm{H}^{+}}=100 ; c_{\mathrm{O}_{2}, \mathrm{aq}}=1.3$ \\
\hline & 14 & & $10^{-5}$ & & & $c_{\mathrm{OH}^{-}}=1000 ; c_{\mathrm{O}_{2}, \mathrm{aq}}=1.3$ \\
\hline
\end{tabular}

7 the selectivity to the desired nitrate reduction products ${ }^{49-51,55-58,82,83}$. It was determined that $\mathrm{Cu}(\mathrm{pH}$ of 14) and $\mathrm{Sn}-\mathrm{Pt}$ ( $\mathrm{pH}$ of 1) exhibited high product selectivity for the reduction of $\mathrm{NO}_{3}{ }^{-}$to $\mathrm{NH}_{3}$ and

$9 \quad \mathrm{~N}_{2} \mathrm{O}$ respectively ${ }^{57,58}$. The kinetics for the NO3RR was modeled by considering the irreversible 10 reduction of $\mathrm{NO}_{3}^{-}$to $\mathrm{NO}_{2}^{-}$as the rate-determining step $^{3,23}$.

$$
\mathrm{NO}_{3}{ }^{-}+\mathrm{H}_{2} \mathrm{O}+2 \mathrm{e}^{-} \rightarrow \mathrm{NO}_{2}^{-}+2 \mathrm{OH}^{-} \quad E^{0}=0.835 \mathrm{~V} \text { v/s NHE }
$$

Because of the high product selectivity (> 98\%) reported for the state-of-the-art catalysts,

12 we assumed full selectivity in the transformation of $\mathrm{NO}_{2}^{-}$to the desired products on the selected

13 catalysts. This is a simplifying assumption to overcome the lack of mechanistic information to

14 model the sequence of elementary steps needed for the various nitrogen-products considered in

15 this study ${ }^{3}$. In the same $\mathrm{pH}$ conditions, the most suitable OER catalysts were identified to be $\mathrm{IrO}_{2}$

$16(\mathrm{pH}=14)$ and $\mathrm{RuO}_{2}(\mathrm{pH}=1)^{33,41,75}$.

17 Modeling Competing Reactions: The electrocatalytic parameters $\left(j_{0, \mathrm{ref}, i}, \alpha_{c, i}, \alpha_{a, i}\right)$ for the 18 competing reactions (ORR and HER) at the cathode were determined such that the impact of the 19 "worst-case" on the efficiency and rates of nitrogen-recovery from the products formed could be 
1 investigated. The largest exchange current density, $j_{0, \text { ref }, i}$, for the competing HER was based on

2 the kinetics reported for Pt at both $\mathrm{pH}=1$ and $\mathrm{pH}=14$ (Table 2). The HER was modeled to be

3 fully reversible with $\alpha_{c}=\alpha_{a}=0.5$, as justified by experimentally reported measurements for various

4 catalysts $^{76,84}$. For the ORR, the $j_{0, \text { ref }, i}$ was selected based on reported values for $\mathrm{Pt}$ for $\mathrm{pH}=1$ and

$5 \quad 14^{78-81}$, and the ORR cathodic charge-transfer coefficient was assumed to be $\alpha_{c}=0.9$ to model a

6 surface that is favorable to ORR. In the headspace of the reactor, standard atmospheric conditions

$7 \quad\left(1 \mathrm{~atm}, 25^{\circ} \mathrm{C}\right)$ with a mole-fraction of $20.9 \%$ of $\mathrm{O}_{2}$, trace amounts of $\mathrm{H}_{2}(0.5 \mathrm{ppm})$ and balance $\mathrm{N}_{2}$

8 was modeled.

9 Overall, we have a consistent system of algebraic equations (up to 12 when competing 10 reactions are included) that are simultaneously solved for the variables $-j_{\mathrm{op}}, V_{\mathrm{op}}, \eta_{\mathrm{OER}, \mathrm{k}}$,

$11 j_{\mathrm{NO} 3 \mathrm{RR}}, \eta_{\mathrm{NO} 3 \mathrm{RR}, \mathrm{k}}, \eta_{\mathrm{NO} O 3 R, \mathrm{mt}}, j_{\mathrm{HER}}, \eta_{\mathrm{HER}, \mathrm{k}}, \eta_{\mathrm{HER}, \mathrm{mt}}, j_{\mathrm{ORR}}, \eta_{\mathrm{ORR}, \mathrm{k}}, \eta_{\mathrm{ORR}, \mathrm{mt}} . \quad$ The system of

12 equations was solved using the fsolve function in Matlab R2018a, with a function tolerance of 10-

$13^{4}$, an optimality tolerance of $10^{-4}$, a step tolerance of $10^{-4}$, an average finite difference step size of

$141.5 \times 10^{-4}$, and with the default solver algorithm (trust-region dogleg) or in instances when the 15 convergence was challenging, the Levenberg-Marquardt algorithm was applied ${ }^{85}$.

16 Performance Metrics: The efficiency of converting the incident solar power (1 Sun or

$171000 \mathrm{~W} \mathrm{~m}^{-2}$ ) to the output chemical power was obtained using Eq. (14), where, $\dot{r}_{i}$ is the molar flux

18 of $\mathrm{NH}_{3}$ and $\mathrm{N}_{2} \mathrm{O}$ produced, and $\Delta \mathrm{g}_{i}^{0}$ is the standard state free-energy change for the respective 19 oxidation reactions (Table 2).

$$
\eta_{\text {solar-to-chemical }, i}=\frac{\dot{r}_{i}\left|\Delta \mathrm{g}_{i}^{0}\right|}{1000} ; i=\mathrm{NH}_{3}, \mathrm{~N}_{2} \mathrm{O}
$$

20 The molar flux, $\dot{r}$, of $\mathrm{NH}_{3}$ and $\mathrm{N}_{2} \mathrm{O}$ (in mol m $\mathrm{m}^{-2} \mathrm{~s}^{-1}$ ) produced is related to the nitrate reduction 21 current density, $j_{\mathrm{NO} O \mathrm{RR}}$, 


$$
\dot{r}_{i}=\frac{\left|j_{\mathrm{NO} 3 \mathrm{RR}}\right|}{n_{e, \text { tot }} F} ; i=\mathrm{NH}_{3}, \mathrm{~N}_{2} \mathrm{O}
$$

1 The oxidation of gaseous $\mathrm{NH}_{3}$ with $\mathrm{O}_{2}$ was modeled, $\Delta \mathrm{g}_{\mathrm{NH}_{3} / \mathrm{H}_{2} \mathrm{O}}^{0}=-339 \mathrm{~kJ} \mathrm{~mol}^{-1}$, whereas gaseous

$2 \mathrm{~N}_{2} \mathrm{O}$ was used as an oxidizer to combust $\mathrm{CH}_{4}, \Delta \mathrm{g}_{\mathrm{CH}_{4}, \mathrm{~N}_{2} \mathrm{O} / \mathrm{H}_{2} \mathrm{O}}^{0}=-308.7 \mathrm{~kJ} \mathrm{~mol}^{-1}$. Solar energy

3 conversion efficiencies for the $\mathrm{NO}_{3}{ }^{-}-$to- $\mathrm{N}_{2}$ transformation is not reported because the $\mathrm{N}_{2}$ produced

4 has to first be reduced to $\mathrm{NH}_{3} / \mathrm{NH}_{4}{ }^{+}$to facilitate energy recovery, and this step in itself is highly

5 energy intense ${ }^{86,87}$. For comparison, when solar-to-hydrogen efficiencies are computed for

6 photoelectrochemical water-splitting devices, the molar rate of $\mathrm{H}_{2}$ production with $\Delta \mathrm{g}_{\mathrm{H}_{2} / \mathrm{H}_{2} \mathrm{O}}^{0}=$ $7 \quad 237.4 \mathrm{~kJ} \mathrm{~mol}^{-1}$ is used.

8 The rate of nitrogen-removal and nitrogen-recovery, $R_{\mathrm{N}}\left(\mathrm{in} \mathrm{g}_{\mathrm{N}} \mathrm{m}^{-2}\right.$ day $^{-1}$ ) are equal and

9 directly proportional to the molar flux, $\dot{r}_{i}$, of the products formed from the nitrate contaminants

10 (Eq. (16)). In Eq. (16), $m_{\mathrm{N}}=14 \mathrm{~g}$, is the molar mass of atomic-nitrogen and $t_{\text {day }}=86400 \mathrm{~s} \mathrm{day}^{-}$

11 . Therefore, a larger solar-to-chemical efficiency is also indicative of improved rates of nitrogen

$12 \mathrm{removal} / \mathrm{recovery}$ in our analyses.

$$
R_{\mathrm{N}}=\dot{r}_{i} m_{\mathrm{N}} t_{\text {day }} ; i=\mathrm{NH}_{3}, \mathrm{~N}_{2} \mathrm{O}
$$

13 The specific energy intensity $E_{\mathrm{N}}\left(\right.$ in $\mathrm{MJ} \mathrm{kgN}_{\mathrm{N}}^{-1}$ ) (Eq. (17)) is a measure of the total energy required

14 per unit mass of nitrogen removed and is commonly used as a metric to compare various

15 technologies from an energy-consumption standpoint. The calculation in Eq. (17) assumed that the

16 device steadily operates at the predicted current-density, $j_{\mathrm{op}}$, and operating potential, $V_{\mathrm{op}}$.

17 Therefore, there is lack of dependence on current-density for the $E_{N}$ calculation, as the current-

18 density term appears both in the numerator (total energy consumption) and the denominator (total

19 mass of nitrogen removed). 


$$
E_{\mathrm{N}}=\frac{V_{\mathrm{op}} n_{e} F}{m_{\mathrm{N}}}
$$

\section{4. Results \& Discussion}

\section{$2 \quad 4.1$ Composition of Nitrogen-Contaminants in Wastewater}

3 Figure 3 shows the source-dependent variability in the composition of nutrient

4 contaminants, including organic, nitrogen and phosphorous contaminants, for various point-

5 sources of wastewater. Point-sources considered in this study included low-level nuclear wastes,

6 municipal wastewater effluents, ion-exchange brines, power generation, and oil/gas and

7 manufacturing processes. Even though diffuse sources, such as agricultural runoff streams and

8 landfill wastewater, also cause nutrient contamination, they are not included in Figure 3 because

9 the contaminant species and concentrations in these sources are strongly influenced by the

10 collection strategy. Biological oxygen demand (BOD) quantifies the amount of the dissolved

11 oxygen required to biologically oxidize the organic contaminants; therefore, the larger the BOD

12 value, the larger the organic contaminant concentration ${ }^{88}$. Nitrogen-species, including $\mathrm{NO}_{3}^{-}, \mathrm{NO}_{2}^{-}$

13 , and $\mathrm{NH}_{4}^{+}$, and phosphates $\left(\mathrm{PO}_{4}^{3-}\right)$ were also considered. Whereas, nitrogen contaminants

14 dominate in nuclear wastes $(159,000 \mathrm{mg} / \mathrm{L}$ total nitrogen species), ion-exchange brines

$15(5,270 \mathrm{mg} / \mathrm{L})$, and power production processes $(300 \mathrm{mg} / \mathrm{L})$, organic species overshadow nutrient

16 contaminants in municipal wastewater effluents and oil/gas processes. The concentrations of all

17 three contaminants are comparable for effluents from manufacturing processes. In many waste

18 streams, $\mathrm{PO}_{4}{ }^{3-}$ contamination is comparable to the nitrogen-contamination, which indicates the

19 potential for phosphorous-recovery from these sources. For reference, the U.S. Environmental

20 Protection Agency (EPA) established nitrogen-contaminant levels for drinking water are $44.3 \mathrm{mg}-$

$21 \mathrm{NO}_{3}-\mathrm{L}$ and $3.3 \mathrm{mg}-\mathrm{NO}_{2}-/ \mathrm{L}^{89}$. 


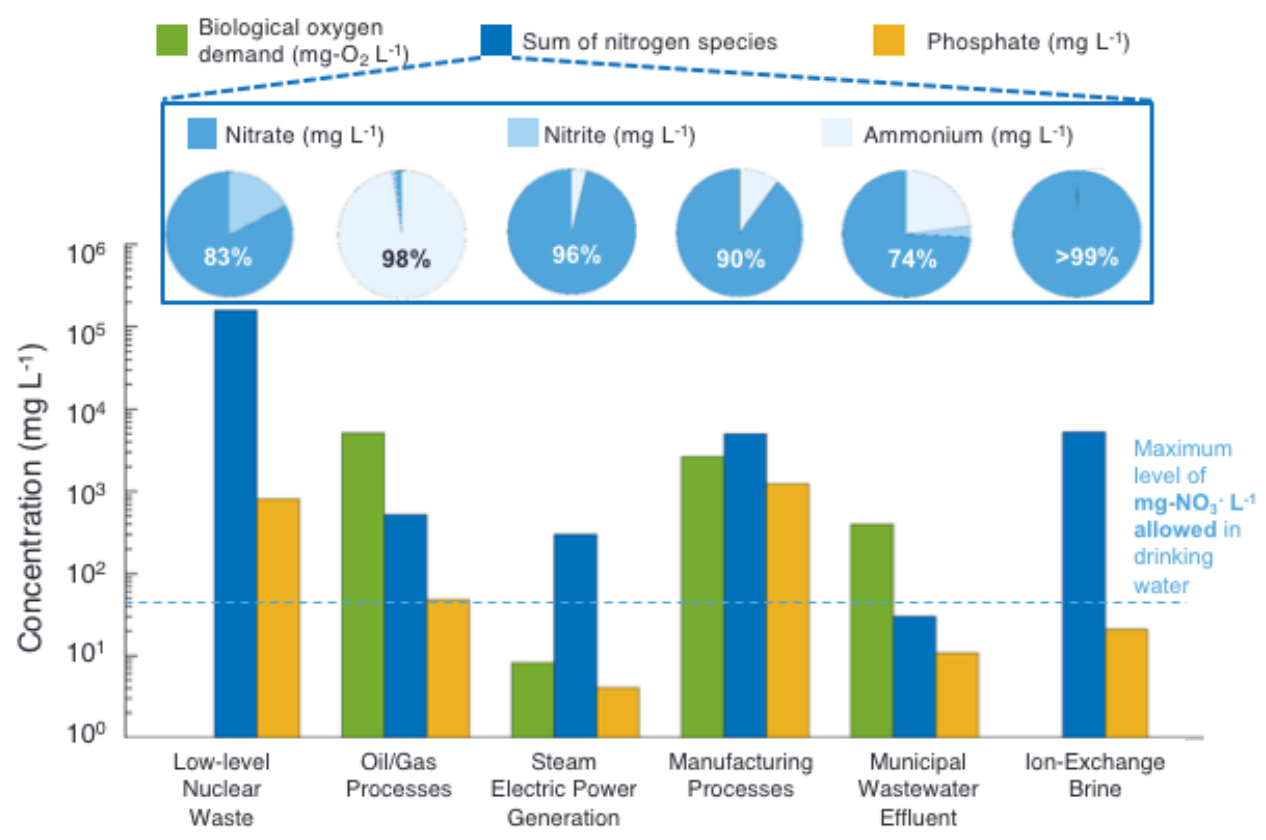

Figure 3: Concentrations of biological oxygen demand $\left(\mathrm{mg}-\mathrm{O}_{2} / \mathrm{L}\right)$, nitrogen species, and phosphate (mg$\left.\mathrm{PO}_{4}{ }^{3-} / \mathrm{L}\right)$ in different waste streams. Percentage breakdown of nitrogen species $-\mathrm{NO}_{3}{ }^{-}\left(\mathrm{mg}-\mathrm{NO}_{3}{ }^{-} / \mathrm{L}\right)$, $\mathrm{NO}_{2}^{-}\left(\mathrm{mg}-\mathrm{NO}_{2}-\mathrm{L}\right)$ and $\mathrm{NH}_{4}{ }^{+}\left(\mathrm{mg}-\mathrm{NH}_{4}{ }^{+} / \mathrm{L}\right)$ is indicated for each source. Data was compiled from the US Environmental Protection Agency (EPA) development documents ${ }^{90,91}$, EPA's database for industrial wastewater treatment technologies ${ }^{92}$, and pertinent journal papers ${ }^{11,13-19,60,93-106}$. EPA's specifications for nitrogen-contaminants in drinking water: $<44.3 \mathrm{mg}-\mathrm{NO}_{3}{ }^{-} / \mathrm{L}$ (dashed blue line) and $<3.3 \mathrm{mg}-\mathrm{NO}_{2}{ }^{-} / \mathrm{L}^{89}$.

1 More than $80 \%$ of all nitrogen-contaminants are in the form of $\mathrm{NO}_{3}{ }^{-}$in all point sources except for oil/gas processes, where the $\mathrm{NH}_{4}{ }^{+}$species predominates. Therefore, tertiary processes targeting

3 nitrogen recovery could be valuable in pre-treated wastewaters from these sources. Furthermore,

4 the source-dependent fluctuation in the $\mathrm{NO}_{3}{ }^{-}$concentration establishes a need to quantify the

5 impacts of this variation on the predicted process efficiencies and the removal/recovery rates.

\subsection{Solar-to-Chemical Efficiencies and Nitrogen Removal/Recovery Rates}

Figure 4 presents the equivalent-circuit model predictions for the solar energy conversion efficiencies (Eq. (14)) for $\mathrm{NH}_{3}$ and $\mathrm{N}_{2} \mathrm{O}$ production as a function of the semiconductor band gaps and electrocatalytic parameters. A bulk $\mathrm{NO}_{3}{ }^{-}$concentration of $100 \mathrm{mM}$, which is approximately the average of the $\mathrm{NO}_{3}{ }^{-}$concentration in the point-source effluents in Figure 3, was used in these 


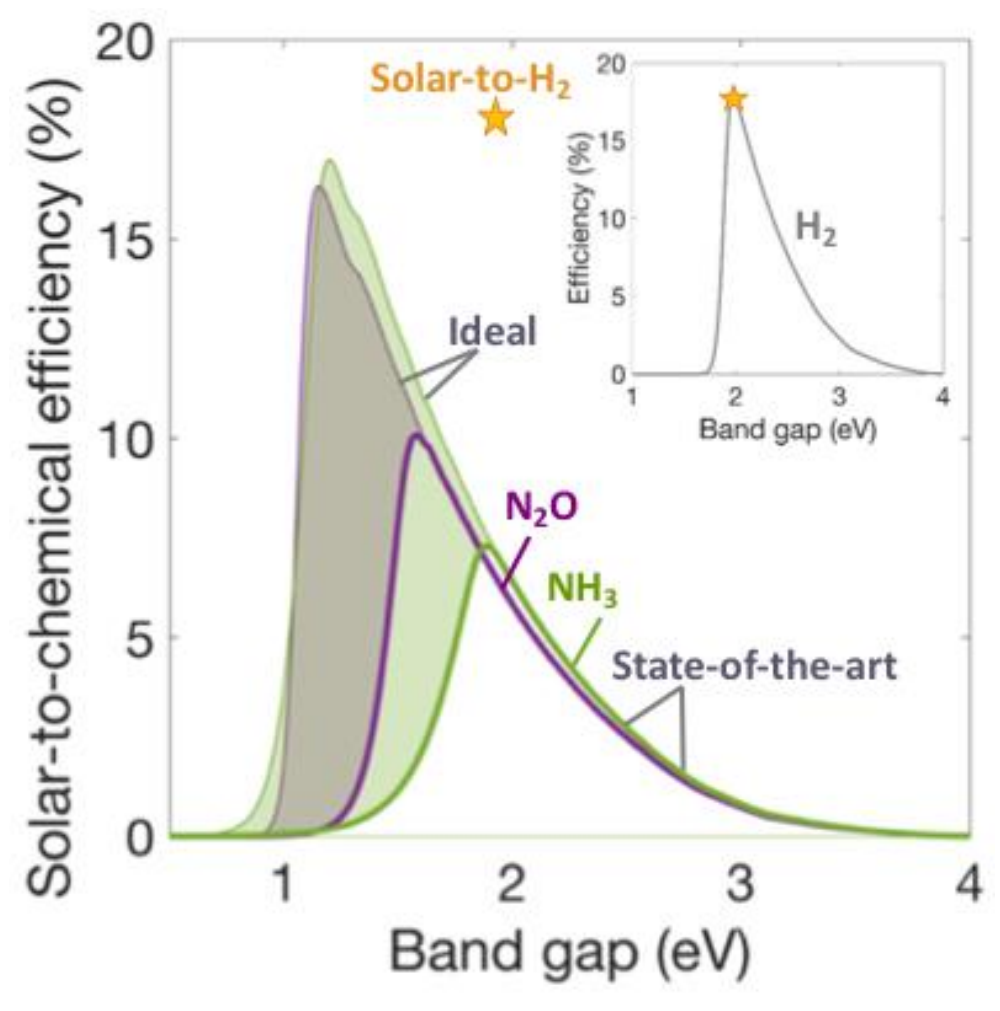

(a)

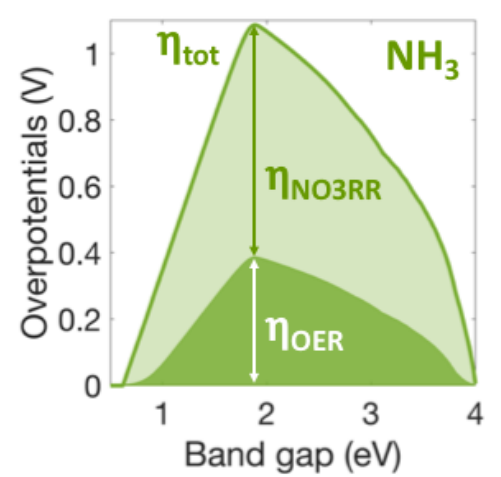

(b)

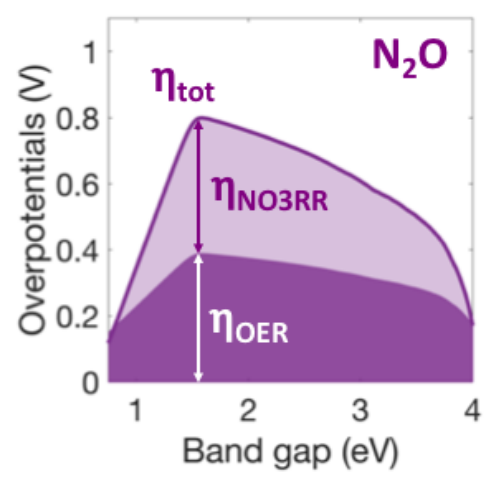

(c)

Figure 4: (a) Solar-to-chemical energy conversion efficiencies, $\eta_{\text {solar-to-chemical }}$, for water oxidation and $\mathrm{NO}_{3}{ }^{-}$reduction to $\mathrm{NH}_{3}$ (green) and $\mathrm{N}_{2} \mathrm{O}$ (purple) with $\mathrm{RuO}_{2}, \mathrm{Cu}\left(\mathrm{pH}\right.$ 14) and $\mathrm{IrO}_{2}, \mathrm{Sn}-\mathrm{Pt}(\mathrm{pH} 1)$ catalysts for the OER and the NO3RR, respectively. Solar-to-hydrogen efficiency in the inset was computed for $\mathrm{RuO}_{2}$ (OER) and $\mathrm{Pt}$ (HER) catalysts at $\mathrm{pH}=1$; maximum solar-to- $\mathrm{H}_{2}$ efficiency is represented as a star ${ }^{38}$. The thick solid lines and the thin solid lines represent efficiencies with state-ofthe-art and ideal nitrate reduction catalysts. Total kinetic overpotential, $\eta_{\text {tot }}$, and the split between the oxidation (OER) overpotential, $\eta_{\text {OER }}$, (dark shaded area) and the NO3RR overpotential, $\eta_{\text {NO3RR }}$, (light shaded area) is shown for (b) $\mathrm{NH}_{3}$ (green) and (c) $\mathrm{N}_{2} \mathrm{O}$ (purple). Standard state potential from Eq. (3) was used and a $100 \mathrm{mM} \mathrm{NO}_{3}{ }^{-}$species concentration was modeled; $E_{\mathrm{NO} O \mathrm{RR}}^{0}=0.835 \mathrm{~V}$ vs NHE .

2 calculations, and selective OER and NO3RR was modeled to estimate the upper limits for the solar energy conversion efficiencies. Irrespective of the catalytic parameters modeled, the solar-to-

4 chemical efficiency initially increases with an increase in the semiconductor band gap until an

5 optimum point, after which, the efficiency decreases. The optimum arises because of the tradeoffs

6 between the increased light absorption for the smaller band gaps and the decreased radiative

7 recombination losses for the larger band gaps. For state-of-the-art catalysts, peak solar-to-chemical 
1 efficiencies are $10.1 \%$ and $7.3 \%$, corresponding to peak nitrogen removal/recovery rates of

$2395.3 \mathrm{gN} \mathrm{m}^{-2}$ day $^{-1}$ and $260.3 \mathrm{gN} \mathrm{m}^{-2}$ day $^{-1}$, for $\mathrm{N}_{2} \mathrm{O}$ and $\mathrm{NH}_{3}$ formation respectively. The trends for

3 the nitrogen removal/recovery rates are not shown in Figure 4 because they exactly match with the

4 trends obtained for the solar-to-chemical efficiencies. The higher efficiencies and recovery-rates

5 for the production of $\mathrm{N}_{2} \mathrm{O}$ relative to $\mathrm{NH}_{3}$ is due to the more effective catalysis for the NO3RR

6 with the Sn-Pt catalyst as compared to $\mathrm{Cu}$. Therefore, at peak efficiencies, relatively smaller kinetic

7 overpotentials resulted for $\mathrm{N}_{2} \mathrm{O}$ as compared to $\mathrm{NH}_{3}-412 \mathrm{mV}$ v/s $689 \mathrm{mV}$ for the NO3RR (Figure

84 (b) and (c)). Ideal efficiency plots were obtained by imposing rapid kinetics for the NO3RR, i.e.

$9 \eta_{\text {red }}=0$, with state-of-the-art OER catalysts. The optimal solar-to-chemical efficiencies for the

10 ideal case more than double, from $7.3 \%$ to $17 \%$, for $\mathrm{NH}_{3}$ and increase from $10.1 \%$ to $16.3 \%$ for

$11 \mathrm{~N}_{2} \mathrm{O}$, as compared to the state-of-the-art NO3RR catalysts. The solar-to-chemical efficiency for

$12 \mathrm{~N}_{2} \mathrm{O}$ formation is relatively less sensitive to the kinetic parameters modeled for NO3RR, as

13 opposed to $\mathrm{NH}_{3}$ formation, because the OER overpotentials dominate the potential losses in the

14 former. This dramatic boost in overall performance, achieved by eliminating the nitrate-reduction

15 kinetic overpotential, indicates that effective nitrate reduction electrocatalysts can significantly

16 boost the efficiencies for any light-absorber and that the performance predictions are highly

17 sensitive to the catalytic parameters modeled. To place these efficiencies in context, Figure 4 also

18 depicts the maximum solar-to-hydrogen conversion efficiency of $18 \%$ for a photoelectrochemical

19 water splitting device with a single light-absorber (band gap of $1.96 \mathrm{eV}$ ) and with state-of-the-art

20 OER and HER catalysts ${ }^{38}$. The optimal efficiencies for the two processes are comparable when

21 ideal/rapid NO3RR reduction kinetics were assumed because the kinetic overpotentials for the

22 state-of-the-art HER catalysts are much smaller than that for the NO3RR catalysts. With state-of-

23 the-art catalysts, the theoretical limits for the peak nitrogen-removal rates are comparable to the 
1 maximum removal rates, of $520 \mathrm{gN} \mathrm{m}^{-2} \mathrm{day}^{-1}$, reported in (bio)electrochemical flow/continuous

2 reactors for ammonia recovery ${ }^{63}$.

3 Figure 5 depicts the effect of varying the bulk $\mathrm{NO}_{3}{ }^{-}$concentration, $c_{\mathrm{NO}_{3}^{-}}$,bulk , on the solar-

4 to-chemical efficiency and the rate of nitrogen removal/recovery, while assuming selective

5 NO3RR catalysis to form $\mathrm{NH}_{3}$ (Figure 5(a) and (c)) or $\mathrm{N}_{2} \mathrm{O}$ (Figure 5(b) and (d)). The bulk

6 concentration of $\mathrm{NO}_{3}{ }^{-}$was varied from $0.1 \mathrm{mM}$ to $1000 \mathrm{mM}$, representing the order-of-magnitude

7 variation in the $\mathrm{NO}_{3}{ }^{-}$concentrations corresponding to the EPA limit in drinking water to the

8 presence of $\mathrm{NO}_{3}$ in concentrated wastewater sources such as ion-exchange brines (Figure 3).

9 Overall, for any concentration modeled, converting the $\mathrm{NO}_{3}{ }^{-}$to $\mathrm{N}_{2} \mathrm{O}$, as compared to $\mathrm{NH}_{3}$, results

10 in larger efficiencies and nitrogen removal/recovery rates $(12.01 \% \mathrm{v} / \mathrm{s} 9.68 \%$ at $1000 \mathrm{mM})$ because

11 of the more effective NO3RR catalysis in the former with Sn-Pt catalysts (Figure 4). There is a

12 logarithmic scaling in the maximum efficiencies and the nitrogen removal/recovery rates with the

$13 \mathrm{NO}_{3}-$ concentration, because of the larger driving force and therefore lower kinetic overpotentials

14 for the electron-transfer reactions (Eq.(12)).

15 For $c_{\mathrm{NO}_{3}^{-}, \text {bulk }}=10,100$ and $1000 \mathrm{mM}$, the transport of $\mathrm{NO}_{3}^{-}$from the bulk solution to the

16 electrode surface does not impact the operating current densities at any band gap of the

17 semiconductor as the mass-transfer limited current density (Eq. (10)) for the NO3RR is much

18 larger than the short-circuit density of the light-absorber. For these concentrations, when the band

19 gaps are smaller than the optimal value, the concentration-dependent NO3RR kinetics limits both

20 the efficiency and nitrogen removal/recovery rates. For the same range of $\mathrm{NO}_{3}{ }^{-}$concentration,

21 when the band gaps are larger than $2 \mathrm{eV}$, the performance is insensitive to changes in the

22 concentration because light-absorption in the semiconductor limits the performance. However, for 


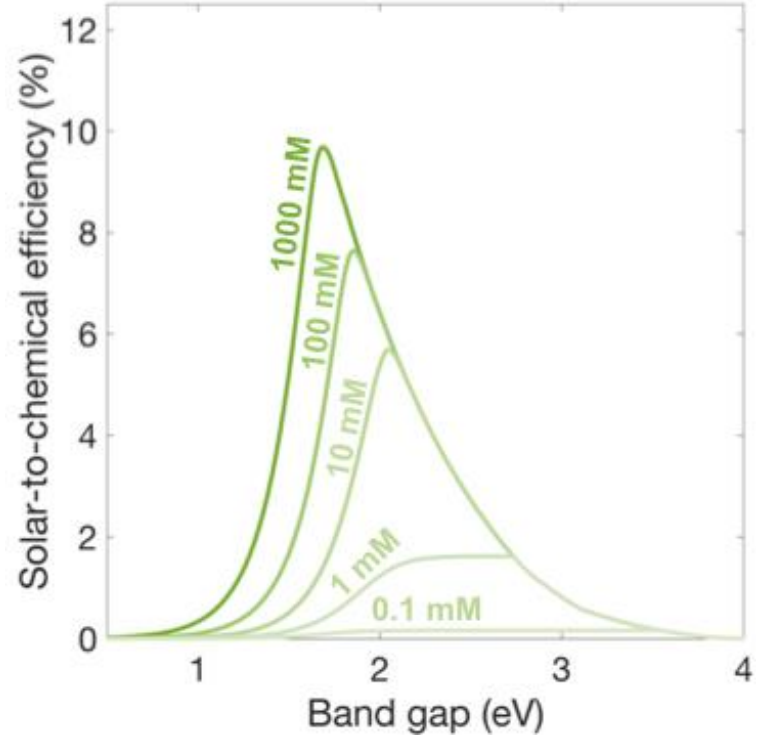

(a)

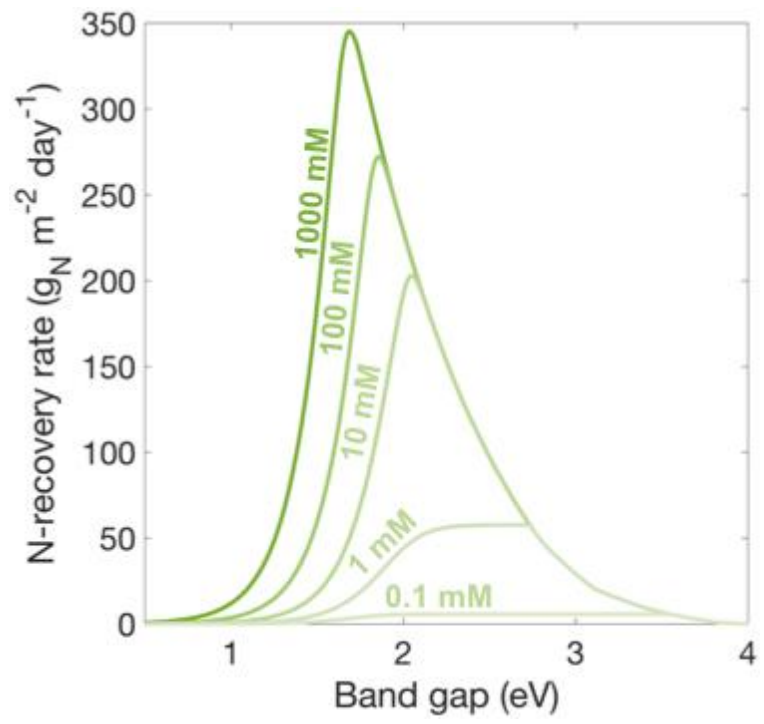

(c)

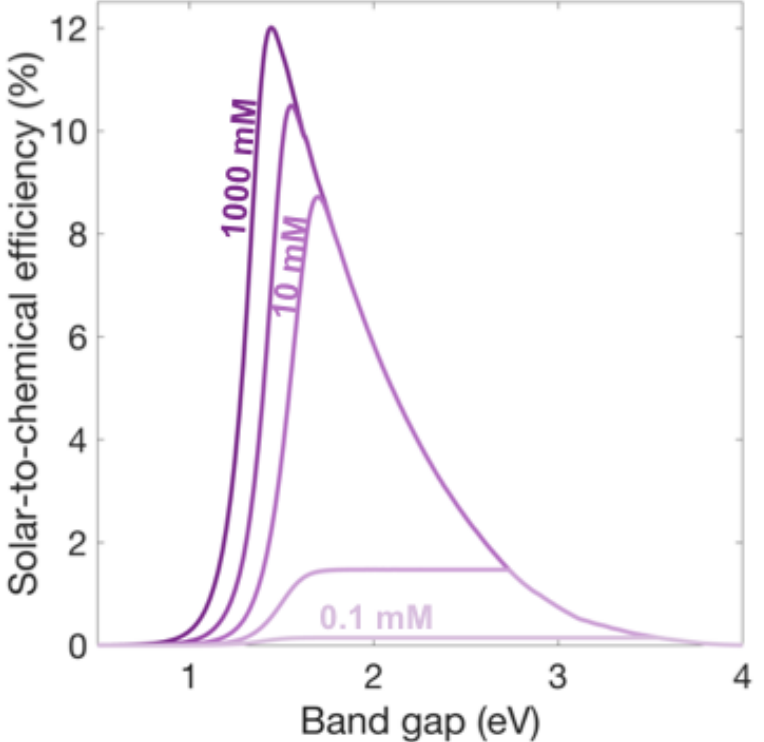

(b)

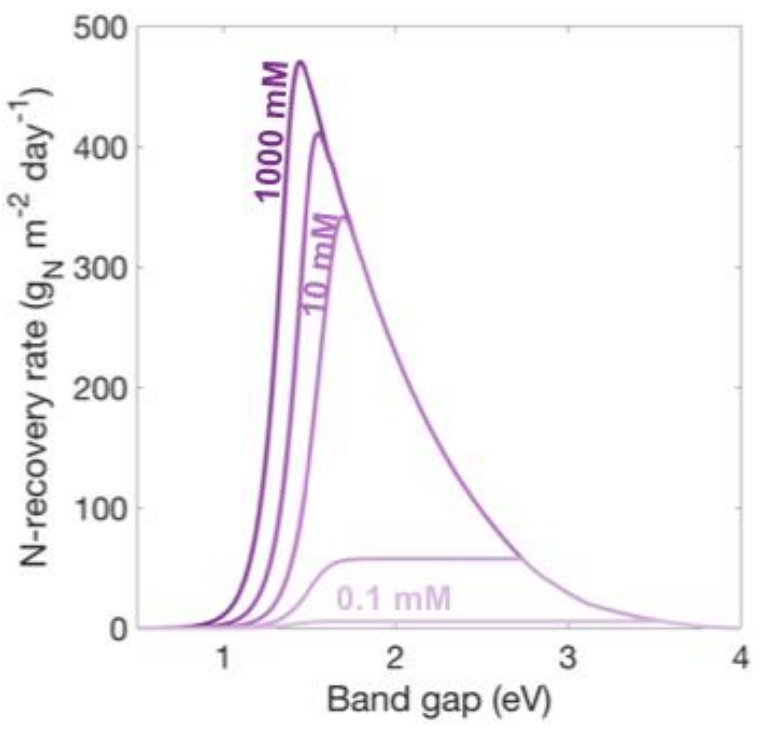

(d)

Figure 5: Concentration effects on the solar-to-chemical efficiencies ((a) and (b)) and the nitrogenremoval rates ((c) and (d)) with complete selectivity to desired reactions assumed: for (a) and (c), for the $\mathrm{NO}_{3}{ }^{-}$-to- $\mathrm{NH}_{3}$ conversion at $\mathrm{pH}$ 14, selective OER on $\mathrm{IrO}_{2}$ and selective $\mathrm{NO} 3 \mathrm{RR}$ on $\mathrm{Cu}$ was assumed; for (b) and (d), for the $\mathrm{NO}_{3}{ }^{-}$-to- $\mathrm{N}_{2} \mathrm{O}$ conversion at $\mathrm{pH}$ 1, selective OER on $\mathrm{RuO}_{2}$ and selective NO3RR on Sn$\mathrm{Pt}$ was assumed. For all these calculations, a headspace with standard atmospheric conditions (1 atm, $\left.25^{\circ} \mathrm{C}\right)$ with $20.9 \%$ of $\mathrm{O}_{2}$, trace amounts of $\mathrm{H}_{2}(0.5 \mathrm{ppm})$ and balance $\mathrm{N}_{2}$ was assumed to determine thermodynamic reaction potentials.

1 the two smaller concentrations, $c_{\mathrm{NO}_{3}^{-} \text {,bulk }}=0.1 \mathrm{mM}$ and $1 \mathrm{mM}$, there is a mass-transfer limited

2 operational regime in addition to the kinetics and light-absorption limited performance. In this

3 regime, there is little-to-no effect of the band gap on the performance, resulting in the plateau 
1 region observed in Figure 5(a) and (b). In these conditions, the operating current density of the

2 device (Eq. (4)), is predominantly limited by the rate of diffusion of the reacting $\mathrm{NO}_{3}{ }^{-}$species from

3 the bulk electrolyte to the electrocatalyst surface. For $\mathrm{NH}_{3}$ production, mass-transfer limited

4 efficiencies of $1.62 \%$ and $0.16 \%$ are predicted for the band gaps of $2.15-2.75 \mathrm{eV}$ and $1.65-$

$5 \quad 2.75 \mathrm{eV}$, with $c_{\mathrm{NO}_{3}^{-}, \text {bulk }}=1 \mathrm{mM}$ and $0.1 \mathrm{mM}$ respectively. Therefore, the bulk $\mathrm{NO}_{3}{ }^{-}$concentration

6 in the waste steam not only has an impact the maximum attainable efficiencies and the nitrogen

7 recovery rates, but also affects how sensitive the performance is to the light-absorber band gaps.

8 Figure 6 reveals the extent to which the competing reactions influences the solar-to-

9 chemical efficiencies. The green and the purple shaded areas (for $\mathrm{NH}_{3}$ and $\mathrm{N}_{2} \mathrm{O}$ respectively)

10 represent the absolute change in efficiency, from assuming selective catalysis to when the worst-

11 case was modeled for the competing reactions. Four discrete band gaps were selected to represent

12 realistic semiconductor materials for the light absorbers- $\mathrm{Si}(1 \mathrm{eV}), \mathrm{MoS}_{2}(1.75 \mathrm{eV}), \mathrm{BiVO}_{4}(2.5$

$13 \mathrm{eV})$, and $\mathrm{TiO}_{2}(3.1 \mathrm{eV})$. Three bulk $\mathrm{NO}_{3}{ }^{-}$concentrations of 1000,10 , and $1 \mathrm{mM}$ were selected to

14 highlight the trends. Consider the results for the $\mathrm{NO}_{3}^{-}$-to- $\mathrm{NH}_{3}$ transformation (Figure 6(a)). For all

15 bandgaps, competing reactions results in lower solar-to-chemical efficiencies and nitrogen

16 removal/recovery rates. The peak efficiencies, from Figure 5 are reduced by $9 \%$ and $63 \%$ for

$171000 \mathrm{mM}$ and $1 \mathrm{mM} \mathrm{NO}_{3}{ }^{-}$respectively. For any band gap, the relative decrease in the efficiency

18 becomes larger when the bulk concentration of $\mathrm{NO}_{3}{ }^{-}$becomes smaller (Figure $\mathrm{S} 1$ in ESI). This

19 outcome is due to the increase in the NO3RR mass-transfer overpotential with a decrease in the

$20 \mathrm{NO}_{3}{ }^{-}$concentration, which in turn increases the driving force for the competing reactions. For the

21 intermediate band gap materials $-\mathrm{MoS}_{2}(1.75 \mathrm{eV})$ and $\mathrm{BiVO}_{4}(2.5 \mathrm{eV})-\mathrm{ORR}$ occurs at the mass-

22 transfer limited current density of $\sim 21 \mathrm{~A} \mathrm{~m}^{-2}$ for all $\mathrm{NO}_{3}{ }^{-}$concentrations (blue circles in Figure 6

23 (b)). However, the rate of competing HER increases when the $\mathrm{NO}_{3}{ }^{-}$concentration decreases 


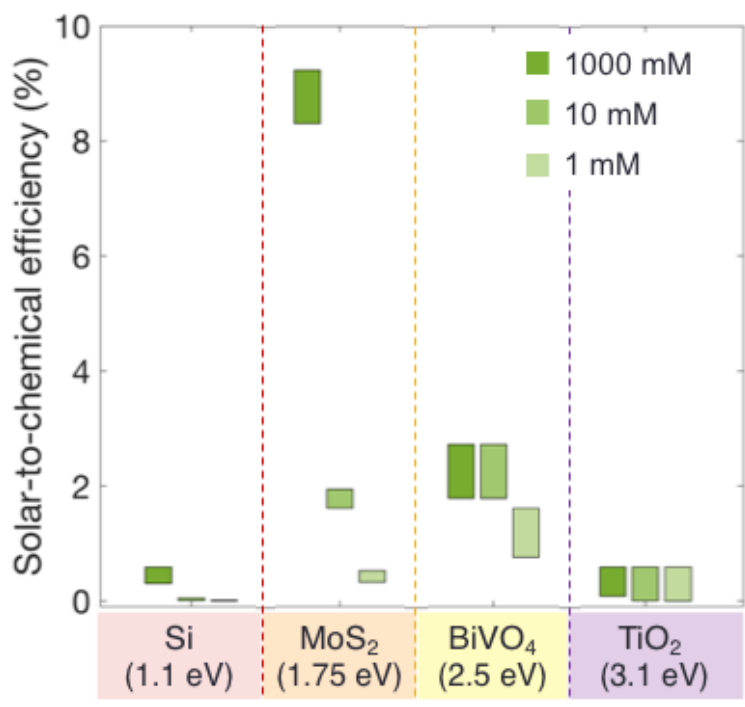

(a)

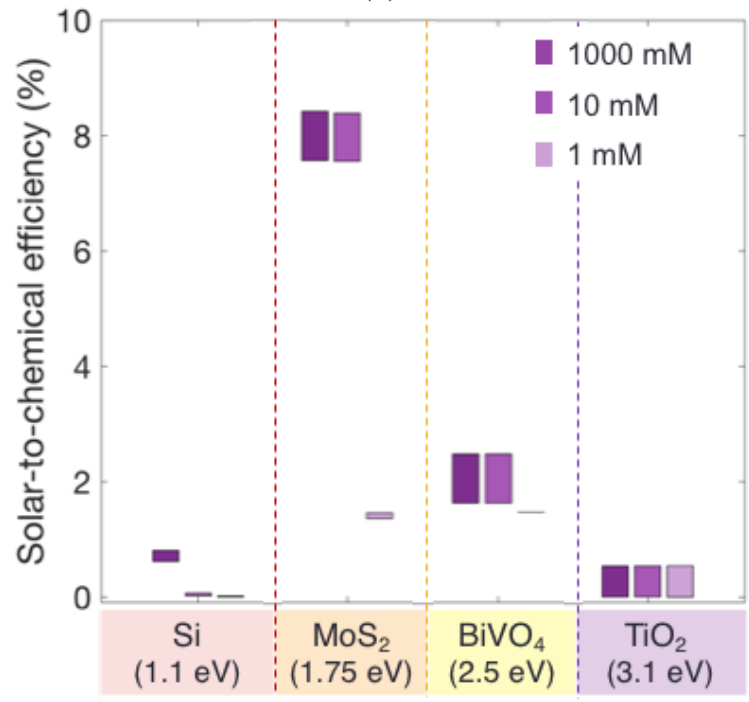

(c)

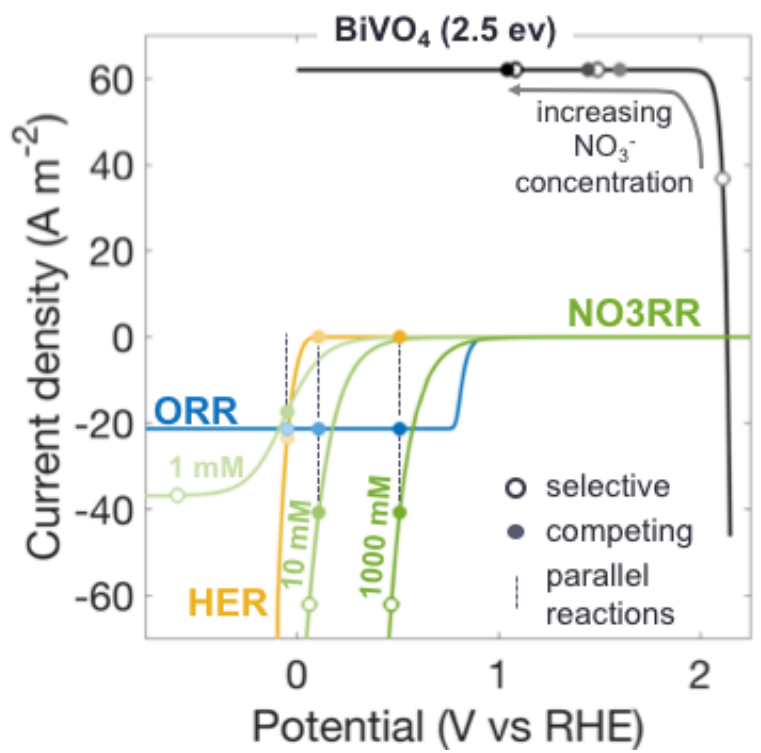

(b)

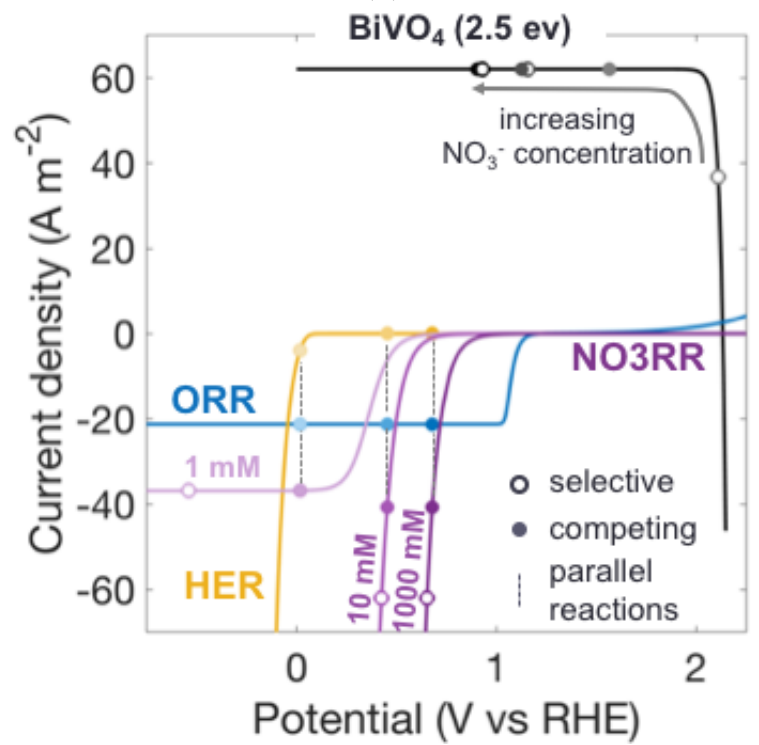

(d)

Figure 6: Solar-to-chemical efficiency for (a) $\mathrm{NH}_{3}$ production and (c) $\mathrm{N}_{2} \mathrm{O}$ production when competing HER and ORR reactions are implemented at the cathode with worst-case kinetic parameter values (Table 2). (b,d) To further illustrate the driving forces for the competing reactions, the current-voltage behavior for the diode (black) assuming $\mathrm{BiVO}_{4}$ with a band gap of $2.5 \mathrm{eV}$ and the parallel and competing electrochemical reactions at the cathode. Open symbols on the current-voltage plot represent models that assumed selective reactions whereas the filled symbols include the competing reactions. The operating point, $\boldsymbol{j}_{\mathbf{o p}}$ and $\boldsymbol{V}_{\mathbf{o p}}$, is shown on the diode curve (black circles); the cathode potential and current densities for (b) $\mathrm{NH}_{3}$ production (green) or (d) $\mathrm{N}_{2} \mathrm{O}$ production (purple); HER (yellow); and ORR (blue). 
1 below $10 \mathrm{mM}$ (yellow circles in Figure 6(b)). For $c_{\mathrm{NO}_{3}^{-} \text {,bulk }}>1 \mathrm{mM}$, mass-transfer limited $\mathrm{H}_{2}$

2 oxidation occurs instead of $\mathrm{H}_{2}$ evolution because the cathode potential is larger than the

3 equilibrium potential of $\mathrm{H}^{+} / \mathrm{H}_{2}, V_{\text {cathode }}>E_{\text {eq,HER }}=0.19 \mathrm{~V} \mathrm{v} / \mathrm{s} \mathrm{RHE}$, assuming a head-space with

$4 \quad 0.5 \mathrm{ppm} \mathrm{H}_{2}$. For a bulk $\mathrm{NO}_{3}{ }^{-}$concentration of $1 \mathrm{mM}$ and a band gap of $2.5 \mathrm{eV}$, while the NO3RR

5 is mass-transfer limited when selective NO3RR was modeled (open green circles in Figure 6(b)),

6 this limitation ceases to exist when competing reactions were taken into account at the cathode

7 (filled green circles in Figure 6(b)). This trend is also evident in the shift of the operating potential

8 and current densities of the diode (open versus closed black circles) on the diode curve in Figure

9 6(b). For both $\mathrm{Si}(1.1 \mathrm{eV})$ and $\mathrm{TiO}_{2}(3.1 \mathrm{eV})$, the baseline efficiencies without the competing

10 reactions are small due to the lack of driving potential at the cathode for the NO3RR in Si and

11 because of the limited visible light absorption for $\mathrm{TiO}_{2}$. In both these instances, mass-transfer

12 limited ORR predominates at the cathode as compared to the NO3RR; $\mathrm{H}_{2}$ oxidation occurs at

13 negligibly small, mass-transfer limited rates of $3.87 \times 10^{-5} \mathrm{~A} \mathrm{~m}^{-2}$, for all $\mathrm{NO}_{3}{ }^{-}$concentrations in

14 the bulk.

15 For the $\mathrm{NO}_{3}{ }^{-}$-to- $\mathrm{N}_{2} \mathrm{O}$ transformation (Figure 6(c)), overall trends are largely similar to what

16 was previously discussed for the $\mathrm{NO}_{3}{ }^{-}$-to- $\mathrm{NH}_{3}$ transformation. A subtle difference occurs with

17 respect to the effects of competing HER for the low $\mathrm{NO}_{3}{ }^{-}$concentrations $(\leq 1 \mathrm{mM})$. While HER

18 becomes more significant at these $\mathrm{NO}_{3}{ }^{-}$concentrations for $\mathrm{NH}_{3}$ production, it is not the case for

$19 \mathrm{~N}_{2} \mathrm{O}$ formation because of the lower kinetic potential losses. Therefore, the current onset occurs at

20 a much lower potential on the $\mathrm{Sn}-\mathrm{Pt}$ catalyst for $\mathrm{N}_{2} \mathrm{O}$ formation as compared to the $\mathrm{Cu}$ catalyst for

$21 \mathrm{NH}_{3}$ production. For example, with the $\mathrm{BiVO}_{4}$ light-absorber with a $2.5 \mathrm{eV}$ bandgap, Figure 6(d)

22 reveals that the NO3RR is mass-transfer limited for, both, with and without competing reactions,

23 and therefore the efficiency does not change (Figure 6(c)). The conversion of $\mathrm{NO}_{3}{ }^{-}$to $\mathrm{N}_{2} \mathrm{O}$ benefits 
1 from more efficient catalytic parameters modeled as compared to $\mathrm{NH}_{3}$, especially at the low $\mathrm{NO}_{3}{ }^{-}$

2 concentrations.

3 Overall, even with large driving forces for the competing reactions established by the

4 worst-case parameters modeled herein, these results indicate that the competing reactions do not

5 significantly influence the performance (at most $10 \%$ relative change in efficiencies and the

6 nitrogen removal/recovery rates) when the $\mathrm{NO}_{3}{ }^{-}$concentrations are large $(\geq 100 \mathrm{mM})$ and with

7 optimally selected band gaps. In these cases, the most dominant competing reaction at the cathode

8 is the ORR, which is mass-transfer-limited to current-densities less than $21 \mathrm{~A} \mathrm{~m}^{-2}$, which is at least

9 five times lesser than the NO3RR current densities.

\subsection{Comparison with state-of-the-art nitrogen-removal technologies}

14 for nitrogen removal and recovery - (1) electrochemical ammonia stripping ${ }^{63}$, and (2) the Sharon-

15 Anammox process that removes $\mathrm{NH}_{3} / \mathrm{NH}_{4}{ }^{+}$contaminants as $\mathrm{N}_{2}{ }^{61,62}$. These three pathways were

16 compared on the basis of the nitrogen-removal rates and the mass-specific energy intensity (Table

17 3). For this comparison, we assumed bulk $\mathrm{NO}_{3}$ concentration of $100 \mathrm{mM}$, state-of-the-art catalysts

18 with perfect selectivity for the NO3RR for $\mathrm{NH}_{3} / \mathrm{NH}_{4}{ }^{+}$production; Figure 6 indicates that the

19 competing reactions do not substantially alter the performance for the $100 \mathrm{mM}$ case. More

20 information about these processes are provided in the ESI (Section 3).

21 For the nitrogen-removal rates, the proposed photoelectrochemical approach achieves

22 nitrogen removal rates comparable to those reported for the electrochemical ammonia-stripping

23 reactors -272.2 and $411.3 \mathrm{gN} \mathrm{m}^{-2}$ day $^{-1}$ for $\mathrm{NH}_{3}$ and $\mathrm{N}_{2} \mathrm{O}$ production respectively with state-of-

24 the-art catalysts and $100 \mathrm{mM}$ bulk $\mathrm{NO}_{3}{ }^{-}$concentration. The Sharon-Anammox is a batch process

25 and thus limited to lower rates of nitrogen removal as compared to the flow reactors, roughly 
$110 \mathrm{gN} \mathrm{m}^{-2}$ day $^{-1}$ (Section 3 in ESI for calculation details). Therefore, the mass-specific energy

2 intensities were compared at this fixed nitrogen removal rate of $10 \mathrm{gN} \mathrm{m}^{-2} \mathrm{day}^{-1}$. About $10-$

$316 \mathrm{MJ} \mathrm{kgN}^{-1}$ is required by the Sharon-Anammox process, including aeration, pumping and other

4 parasitic power inputs at the plant-scale $e^{61,62}$. A specific energy intensity of $\sim 2.4 \mathrm{MJ} \mathrm{kgN}^{-1}$ is

5 estimated, without any consideration of parasitic energy requirements, for the electrochemical

6 ammonia stripping reactor ${ }^{63}$. In comparison, at equivalent nitrogen-removal rates, the energy

7 intensity for the photoelectrochemical approach proposed in this work is $8 \mathrm{MJ} \mathrm{kgN}^{-1}$, out of which

$82.9 \mathrm{MJ} \mathrm{kgN}^{-1}$ is required for the $\mathrm{NO}_{3}^{-}-$to- $-\mathrm{NH}_{4}{ }^{+}$transformation, $2.6 \mathrm{MJ} \mathrm{kgN}^{-1}$ is estimated for

9 pumping in a flow reactor ${ }^{98}$, and an energy requirement of $2.4 \mathrm{MJ} \mathrm{kgN}^{-1}$ was additionally included

10 to recover the $\mathrm{NH}_{3} / \mathrm{NH}_{4}{ }^{+}$formed via electrochemical ammonia stripping. Therefore, the proposed

11 approach has the potential to competitive with one of the most energy-efficient nitrogen-removal

12 technologies with the added dual benefits of harnessing sunlight to treat and remove reactive-

13 nitrogen $\left(\mathrm{NO}_{3}^{-}\right)$contaminants while also recovering nutrients as $\mathrm{NH}_{3} / \mathrm{NH}_{4}{ }^{+}\left(\right.$or $\left.\mathrm{N}_{2} \mathrm{O}\right)$.

14 Table 3: Nitrogen-removal rates and mass-specific energy intensity comparisons for the Sharon15 Annamox, electrochemical flow reactor for ammonia stripping and the photoelectrochemical 16 approach discussed in this work.

\begin{tabular}{lccc}
\hline & \multicolumn{3}{c}{ Nitrogen-removal Technologies } \\
\cline { 2 - 4 } Metrics (Units) & $\begin{array}{c}\text { Sharon- } \\
\text { Anammox }\end{array}$ & $\begin{array}{c}\text { Electrochemical flow } \\
\text { reactor for ammonia } \\
\text { stripping }\end{array}$ & $\begin{array}{c}\text { Photoelectrochemical device } \\
\text { for nitrate-to-ammonia } \\
\text { conversion (this work) }\end{array}$ \\
\hline $\begin{array}{l}\text { Nitrogen-removal rates } \\
\left(\mathrm{g}_{\mathrm{N}} \mathrm{m}^{-2} \text { day }\right.\end{array}$ & 10 & 384 & 272.2 \\
\hline $\begin{array}{l}\text { Mass-specific energy } \\
\text { intensity }\left(\mathrm{MJ} \mathrm{kg}_{\mathrm{N}}^{-1}\right) \text { for } \\
\text { nitrogen removal at a } \\
\text { rate of } 10 \mathrm{~g}_{\mathrm{N}} \mathrm{m}^{-2} \text { day }^{-1}\end{array}$ & $10-16$ & 2.4 & 8 \\
\hline
\end{tabular}

\section{5. Conclusions}

18 In summary, we propose and analyze the performance of a solar-powered wastewater

19 nitrate treatment process that couples water oxidation with nitrate reduction to produce value- 
1 added chemicals such as $\mathrm{NH}_{4}+/ \mathrm{NH}_{3}$ and $\mathrm{N}_{2} \mathrm{O}$. A numerical model was developed to predict the

2 influences of material- and operational- parameters on solar-to-chemical efficiencies and the

3 nitrogen removal/recovery rates. Important modeling innovations were introduced to quantify the

4 influences of reacting species concentrations in the bulk solution and the competing hydrogen

5 evolution and oxygen reduction reactions on the performance. Results reveal that the overall

6 performance of the proposed device is influenced by the combined effects of light absorption in

7 the semiconductor, which was modeled as a function of the band gap; electrocatalytic parameters

8 including the exchange current densities and charge-transfer coefficients for the water oxidation

9 and nitrate reduction reactions; and the species concentrations, which impacted the rates of

10 diffusion of species across the concentration boundary layer.

11 For a bulk $\mathrm{NO}_{3}$ concentration of $100 \mathrm{mM}$, model results predict peak solar-to-chemical 12 efficiencies of $7 \%$ and $10 \%$, and nitrogen removal/recovery rates of $260 \mathrm{gN} \mathrm{m}^{-2} \mathrm{day}^{-1}$ and

$13395 \mathrm{gN} \mathrm{m}^{-2}$ day $^{-1}$, for $\mathrm{NH}_{3}$ and $\mathrm{N}_{2} \mathrm{O}$ production with $\mathrm{Cu}$ and $\mathrm{Sn}-\mathrm{Pt}$ catalysts respectively; optimal

14 light-absorber band gaps are $1.89 \mathrm{eV}$ and $1.58 \mathrm{eV}$ respectively. The reacting $\mathrm{NO}_{3}{ }^{-}$species

15 concentration impacts the reaction kinetics by influencing the concentration-dependent exchange-

16 current densities and the mass-transfer limited nitrate reduction current densities. For $\mathrm{NO}_{3}{ }^{-}$

17 concentrations larger than or equal to $10 \mathrm{mM}$, efficiencies and the nitrogen removal/recovery rates

18 are limited by the nitrate reduction kinetics or the light-absorber current-voltage behavior.

19 However, for the smaller $\mathrm{NO}_{3}{ }^{-}$concentrations, there is a mass-transfer limited operating regime,

20 wherein the efficiencies and the nitrogen removal/recovery rates are unaffected by changes in the

21 light-absorber band gap and the electrocatalytic parameters. In this regime, the operating current

22 densities are only limited by the rate of diffusion of the $\mathrm{NO}_{3}{ }^{-}$ions, from the bulk to the surface of

23 the electrocatalyst across a $10-\mu \mathrm{m}$ thick concentration boundary layer. Competing hydrogen 
1 evolution and oxygen reduction reactions were modeled with worst-case parameters deduced from

2 kinetics for these reactions on a Pt-catalyst. For large concentrations $(\geq 100 \mathrm{mM})$ of nitrates and 3 optimally selected light-absorber band gaps, oxygen reduction is the more dominant competing

4 reaction and is mass-transfer limited. Therefore, the peak efficiencies and the nitrogen

5 removal/recovery rates are at most reduced by $11 \%$. The driving force for the hydrogen evolution

6 reaction increases for the smaller $\mathrm{NO}_{3}{ }^{-}$concentrations and for increasing light-absorber band gaps.

7 Model predictions were used to identify light-absorber materials, based on the calculated

8 effects of their band gaps, for $\mathrm{NH}_{3}$ and $\mathrm{N}_{2} \mathrm{O}$ production. For example, $\mathrm{MoS}_{2}$ with a band gap of

$9 \quad 1.75 \mathrm{eV}$ can yield high efficiencies and nitrogen removal rates for $\mathrm{NO}_{3}^{-}$-to- $\mathrm{NH}_{3}$ conversion, when

$10 \mathrm{NO}_{3}$ concentrations are larger than $10 \mathrm{mM}$. When the concentration becomes smaller, even with a

11 larger band gap light-absorber, such as $\mathrm{BiVO}_{4}(2.5 \mathrm{eV})$, the efficiency remains unaffected.

12 Theoretical predictions for the performance of the proposed photoelectrochemical device in

13 attractive when compared with the state-of-the-art nitrogen removal technologies. A comparative

14 analysis revealed that the nitrogen removal rate and the energy intensity of nitrogen-removal are

15 competitive with reported estimates for electrochemical ammonia stripping and the Sharon-

16 Anammox process.

17 On the whole, theoretical analyses in this study indicate that transforming wastewater

18 nitrates to value-added chemicals, including $\mathrm{NH}_{3}$ and $\mathrm{N}_{2} \mathrm{O}$, by utilizing sunlight can be a promising

19 new approach to achieve resource recovery in tertiary wastewater treatment technologies. Future

20 investigations will focus on experimental measurements to further build on this work and to assess

21 the performance of the catalysts and semiconductor materials identified in this work. 


\section{Acknowledgments}

Financial support from the Department of Mechanical Engineering start-up funds and the

4 M-Cubed Grant from the College of Engineering at the University of Michigan are gratefully 5 acknowledged. Barrera was in part supported by the U.S. Department of Energy, Office of Energy

6 Efficiency and Renewable Energy, Fuel Cell Technologies Office, under the Award No. DE-

7 EE0008838. The authors also thank Prof. Shane Ardo at the University of California, Irvine, on

8 the helpful discussions regarding the implementation of competing redox reactions for

9 photoelectrochemical systems, and Prof. Steven Skerlos at the University of Michigan for his

10 insights to establish comparisons of metrics across various nitrogen-removal technologies. 


\section{References}

2 1. Rockström, J. et al. A safe operating space for humanity. Nature 461, 472-475 (2009).

3 2. Gao, H., Scherson, Y. D. \& Wells, G. F. Towards energy neutral wastewater treatment: 4 methodology and state of the art. Environ. Sci. Process. Impacts 16, 1223-1246 (2014).

5 3. Duca, M. \& Koper, M. T. M. Powering denitrification: the perspectives of electrocatalytic

4. Falkowski, P. et al. The Global Carbon Cycle : A Test of Our Knowledge of Earth as a System. Science (80-. ). 290, 291-297 (2000).

5. Kapoor, A. \& Viraraghavan, T. Nitrate Removal From Drinking Water-Review. $J$.

6. Heisler, J. et al. Eutrophication and harmful algal blooms: A scientific consensus. Harmful Algae 8, 3-13 (2008).

7. Terblanche, A. P. S. Health hazards of nitrate in drinking water. Water SA vol. 17 77-82 (1991).

8. Gruber, N. \& Galloway, J. N. An Earth-system perspective of the global nitrogen cycle. Nature 451, 293-296 (2008).

9. Scherson, Y. D. et al. Nitrogen removal with energy recovery through N2O decomposition. Energy Environ. Sci. 6, 241-248 (2013).

10. Schreiber, F., Wunderlin, P., Udert, K. M. \& Wells, G. F. Nitric oxide and nitrous oxide turnover in natural and engineered microbial communities: biological pathways, chemical reactions, and novel technologies. Front. Microbiol. 3, 1-24 (2012).

11. National Research Council. Municipal Wastewater, Sewage Sludge, and Agriculture. in Use of Reclaimed Water and Sludge in Food Crop Production 17-45 (The National Academies Press, 1996).

12. Puyol, D. et al. Resource recovery from wastewater by biological technologies: Opportunities, challenges, and prospects. Front. Microbiol. 7, 1-23 (2017).

13. Huo, X., Vanneste, J., Cath, T. Y. \& Strathmann, T. J. A hybrid catalytic hydrogenation/membrane distillation process for nitrogen resource recovery from nitratecontaminated waste ion exchange brine. Water Res. 175, 115688 (2020).

14. Liu, J., Choe, J. K., Sasnow, Z., Werth, C. J. \& Strathmann, T. J. Application of a Re-Pd bimetallic catalyst for treatment of perchlorate in waste ion-exchange regenerant brine. Water Res. 47, 91-101 (2013).

15. Van Ginkel, S. W., Tang, Y. \& Rittmann, B. E. Impact of precipitation on the treatment of real ion-exchange brine using the H2-based membrane biofilm reactor. Water Sci. Technol. 63, 1453-1458 (2011).

16. Yang, T., Doudrick, K. \& Westerhoff, P. Photocatalytic reduction of nitrate using titanium dioxide for regeneration of ion exchange brine. Water Res. 47, 1299-1307 (2013).

17. Nichols, K. M., Miles-Richardson, S. R., Snyder, E. M. \& Giesy, J. P. Effects of exposure to municipal wastewater in situ on the reproductive physiology of the fathead minnow (Pimephales promelas). Environ. Toxicol. Chem. 18, 2001-2012 (1999).

18. Odjadjare, E. E. O. \& Okoh, A. I. Physicochemical quality of an urban municipal wastewater effluent and its impact on the receiving environment. Environ. Monit. Assess. 170, 383-394 (2010).

19. Katz, B. G., Griffin, D. W. \& Davis, J. H. Groundwater quality impacts from the land application of treated municipal wastewater in a large karstic spring basin: Chemical and microbiological indicators. Sci. Total Environ. 407, 2872-2886 (2009). 
20. S. Pabi L. Reekie, Amarnath, A., Goldstein, R. \& Reekie, L. Electricity Use and Management in the Municipal Water Supply and Wastewater Industries. Epri 1-194 (2013).

21. United States Environmental Protection Agency. Case Studies on Implementing Low-Cost Modifications to Improve Nutrient Reduction at Wastewater Treatment Plants. United States Environ. Prot. Agency, Off. Wetl. Ocean. Watersheds, Off. Sci. Technol. Off. Wastewater Manag. 22 (2015).

22. U.S. Environmental Protection Agency. Energy Efficiency in Water and Wastewater Facilities: A Guide to Developing and Implementing Greenhouse Gas Reduction Programs. (2013).

23. Rosca, V., Duca, M., de Groot, M. T. \& Koper, M. T. M. Nitrogen Cycle Electrocatalysis. Chem. Rev. 109, 2209-2244 (2009).

24. Dahab, M. F. Nitrate Treatment Methods: An Overview. in Nitrate Contamination: Exposure, Consequence, and Control (eds. Bogardi, I. \& Kuzelka, R. D.) 351-369 (NATO ASI Series, 1991).

25. Lehman, S. G., Badruzzaman, M., Adham, S., Roberts, D. J. \& Clifford, D. A. Perchlorate and nitrate treatment by ion exchange integrated with biological brine treatment. Water Res. 42, 969-976 (2008).

26. Clifford, D., Lin, C.-C., Horng, L.-L. \& Boegel, J. Nitrate Removal from Drinking Water in Glendale, Arizona. (1987).

27. Kneifel, K., Lührs, G. \& Wagner, H. Nitrate Removal by Electrodialysis for Brewing Water. Desalination 68, 203-209 (1988).

28. Bohdziewicz, J., Bodzek, M. \& Wạsik, E. The application of reverse osmosis and nanofiltration to the removal of nitrates from groundwater. Desalination 121, 139-147 (1999).

29. Shaffer, D. L., Yip, N. Y., Gilron, J. \& Elimelech, M. Seawater desalination for agriculture by integrated forward and reverse osmosis: Improved product water quality for potentially less energy. J. Memb. Sci. 415-416, 1-8 (2012).

30. Samatya, S., Kabay, N., Yüksel, Ü., Arda, M. \& Yüksel, M. Removal of nitrate from aqueous solution by nitrate selective ion exchange resins. React. Funct. Polym. 66, 12061214 (2006).

31. Shaner, M. R., Fountaine, K. T. \& Lewerenz, H.-J. Current-voltage characteristics of coupled photodiode-electrocatalyst devices. Appl. Phys. Lett. 103, 143905 (2013).

32. Winkler, M. T., Cox, C. R., Nocera, D. G. \& Buonassisi, T. Modeling integrated photovoltaic - electrochemical devices using steady-state equivalent circuits. Natl. Acad. Sci. (2013) doi:10.1073/pnas.1301532110.

33. Bala Chandran, R., Breen, S., Shao, Y., Ardo, S. \& Weber, A. Z. Evaluating particlesuspension reactor designs for Z-scheme solar water splitting via transport and kinetic modeling. Energy Environ. Sci. 11, 115-135 (2018).

34. Keene, S., Bala Chandran, R. \& Ardo, S. Calculations of theoretical efficiencies for electrochemically-mediated tandem solar water splitting as a function of bandgap energies and redox shuttle potential. Energy Environ. Sci. 12, 261-272 (2019).

35. Fountaine, K. T., Lewerenz, H. J. \& Atwater, H. A. Efficiency limits for photoelectrochemical water-splitting. Nat. Commun. 7, 13706 (2016).

36. Shockley, W. \& Queisser, H. J. Detailed Balance Limit of Efficiency of p-n Junction Solar Cells. J. Appl. Phys. 32, 510-519 (1961). 
37. Xiang, C. et al. Modeling, Simulation, and Implementation of Solar-Driven WaterSplitting Devices. Angew. Chemie Int. Ed. 55, 12974-12988 (2016).

38. Hu, S., Xiang, C., Haussener, S., Berger, A. D. \& Lewis, N. S. An analysis of the optimal band gaps of light absorbers in integrated tandem photoelectrochemical water-splitting systems. Energy Environ. Sci. 6, 2984 (2013).

39. Wang, Q., Hisatomi, T., Ma, S. S. K., Li, Y. \& Domen, K. Core/shell structured La- and Rh-Codoped SrTiO3 as a hydrogen evolution photocatalyst in Z-scheme overall water splitting under visible light irradiation. Chem. Mater. 26, 4144-4150 (2014).

40. McCrory, C. C. L., Jung, S., Peters, J. C. \& Jaramillo, T. F. Benchmarking Heterogeneous Electrocatalysts for the Oxygen Evolution Reaction. J. Am. Chem. Soc. 135, 16977-16987 (2013).

41. Jung, S., McCrory, C. C. L., Ferrer, I. M., Peters, J. C. \& Jaramillo, T. F. Benchmarking nanoparticulate metal oxide electrocatalysts for the alkaline water oxidation reaction. $J$. Mater. Chem. A 4, 3068-3076 (2016).

42. McCrory, C. C. L. et al. Benchmarking Hydrogen Evolving Reaction and Oxygen Evolving Reaction Electrocatalysts for Solar Water Splitting Devices. J. Am. Chem. Soc. 137, 4347-4357 (2015).

43. Tugaoen, H. O., Garcia-Segura, S., Hristovski, K. \& Westerhoff, P. Challenges in photocatalytic reduction of nitrate as a water treatment technology. Sci. Total Environ. 599-600, 1524-1551 (2017).

44. Wehbe, N. et al. Comparative study of photocatalytic and non-photocatalytic reduction of nitrates in water. Appl. Catal. A Gen. 368, 1-8 (2009).

45. Marks, R., Yang, T., Westerhoff, P. \& Doudrick, K. Comparative analysis of the photocatalytic reduction of drinking water oxoanions using titanium dioxide. Water Res. 104, 11-19 (2016).

46. Loeb, S. K. et al. The Technology Horizon for Photocatalytic Water Treatment: Sunrise or Sunset? Environ. Sci. Technol. 53, 2937-2947 (2019).

47. Garcia-Segura, S., Lanzarini-Lopes, M., Hristovski, K. \& Westerhoff, P. Electrocatalytic reduction of nitrate: Fundamentals to full-scale water treatment applications. Appl. Catal. B Environ. 236, 546-568 (2018).

48. Barrabés, N. \& Sá, J. Catalytic nitrate removal from water, past, present and future perspectives. Appl. Catal. B Environ. 104, 1-5 (2011).

49. Yang, J., Calle-Vallejo, F., Duca, M. \& Koper, M. T. M. Electrocatalytic reduction of nitrate on a Pt electrode modified by p-block metal adatoms in acid solution.

ChemCatChem 5, 1773-1783 (2013).

50. Chen, T., Li, H., Ma, H. \& Koper, M. T. M. Surface Modi fi cation of Pt ( 100 ) for Electrocatalytic Nitrate Reduction to Dinitrogen in Alkaline Solution. 2, (2015).

51. Gootzen, J. F. E., Lefferts, L. \& van Veen, J. A. R. Electrocatalytic nitrate reduction on palladium based catalysts activated with germanium. Appl. Catal. A Gen. 188, 127-136 (1999).

52. Martínez, J., Ortiz, A. \& Ortiz, I. Environmental State-of-the-art and perspectives of the catalytic and electrocatalytic reduction of aqueous nitrates. "Applied Catal. B, Environ. 207, 42-59 (2017).

53. Dortsiou, M., Katsounaros, I., Polatides, C. \& Kyriacou, G. Electrochemical removal of nitrate from the spent regenerant solution of the ion exchange. Desalination 248, 923-930 (2009). 
54. Bergmann, H., Bouzek, K., Paidar, M. \& Sadiâlkova, a. Electrochemical reduction of nitrate in weakly alkaline solutions. J. Appl. Electrochem. 31, 1185-1193 (2001).

55. Kuang, P., Natsui, K. \& Einaga, Y. Comparison of performance between boron-doped diamond and copper electrodes for selective nitrogen gas formation by the electrochemical reduction of nitrate. Chemosphere 210, 524-530 (2018).

56. Cattarin, S. Electrochemical reduction of nitrogen oxyanions in $1 \mathrm{M}$ sodium hydroxide solutions at silver, copper and CuInSe2 electrodes. J. Appl. Electrochem. 22, 1077-1081 (1992).

57. Reyter, D., Bélanger, D. \& Roué, L. Study of the electroreduction of nitrate on copper in alkaline solution. Electrochim. Acta 53, 5977-5984 (2008).

58. Yang, J., Duca, M., Schouten, K. J. P. \& Koper, M. T. M. Formation of volatile products during nitrate reduction on a Sn-modified Pt electrode in acid solution. J. Electroanal. Chem. 662, 87-92 (2011).

59. Katsounaros, I., Ipsakis, D., Polatides, C. \& Kyriacou, G. Efficient electrochemical reduction of nitrate to nitrogen on tin cathode at very high cathodic potentials. Electrochim. Acta 52, 1329-1338 (2006).

60. Genders, J. D., Hartsough, D. \& Hobbs, D. T. Electrochemical reduction of nitrates and nitrites in alkaline nuclear waste solutions. J. Appl. Electrochem. 26, 1-9 (1996).

61. Lackner, S. et al. Full-scale partial nitritation/anammox experiences - An application survey. Water Res. 55, 292-303 (2014).

62. Maurer, M., Schwegler, P. \& Larsen, T. A. Nutrients in urine: Energetic aspects of removal and recovery. Water Sci. Technol. 48, 37-46 (2003).

63. Kuntke, P. et al. (Bio)electrochemical ammonia recovery: progress and perspectives. Appl. Microbiol. Biotechnol. 102, 3865-3878 (2018).

64. Zamfirescu, C. \& Dincer, I. Using ammonia as a sustainable fuel. 185, 459-465 (2008).

65. Lan, R. \& Tao, S. Ammonia as a Suitable Fuel for Fuel Cells. Front. Energy Res. 2, 35 (2014).

66. Afif, A. et al. Ammonia-fed fuel cells: A comprehensive review. Renew. Sustain. Energy Rev. 60, 822-835 (2016).

67. Scherson, Y. D. et al. Nitrogen removal with energy recovery through $\mathrm{N} 2 \mathrm{O}$ decomposition. Energy Environ. Sci. 6, 241-248 (2013).

68. Parmon, V. N., Panov, G. I., Uriarte, A. \& Noskov, A. S. Nitrous oxide in oxidation chemistry and catalysis: application and production. Catal. Today 100, 115-131 (2005).

69. Plieth, W. J. Nitrogen. in Encyclopedia of Electrochemistry of the Elements, Vol. VIII (ed. Bard, A. J.) 321-479 (Marcel Dekker, Inc., 1978).

70. Singh, N. \& Goldsmith, B. R. Role of Electrocatalysis in the Remediation of Water Pollutants. ACS Catal. 3365-3371 (2020) doi:10.1021/acscatal.9b04167.

71. Lide, D. R. Standard Thermodynamic Properties of Chemical Substances. in CRC Handbook of Chemistry and Physics (ed. David R. Lide) 5-22 (CRC Press, 2005).

72. Reyter, D. et al. Nitrate removal by a paired electrolysis on copper and $\mathrm{Ti} / \mathrm{IrO} 2$ coupled electrodes - Influence of the anode/cathode surface area ratio. Water Res. 44, 1918-1926 (2010).

73. Deng, J. et al. Nanowire Photoelectrochemistry. Chem. Rev. 119, 9221-9259 (2019).

74. Bard, A. J. \& Faulkner, L. R. Electrochemical Methods Fundamentals and Applications. (John Wiley \& Sons, Inc., 2001).

45

46

75. Chang, C. \& Wen, T. Kinetics of Oxygen Reduction at IrO2-Coated Titanium Electrode in 
Alkaline Solution. J. Electrochem. Soc. 143, 1485-1491 (1996).

76. Sheng, W., Gasteiger, H. A. \& Shao-Horn, Y. Hydrogen Oxidation and Evolution Reaction Kinetics on Platinum: Acid vs Alkaline Electrolytes. J. Electrochem. Soc. 157, B1529 (2010).

77. Sheng, W., Myint, M., Chen, J. G. \& Yan, Y. Correlating the hydrogen evolution reaction activity in alkaline electrolytes with the hydrogen binding energy on monometallic surfaces. Energy Environ. Sci. 6, 1509-1512 (2013).

78. Macia, M. D., Campina, J. M., Herrero, E. \& Feliu, J. M. On the kinetics of oxygen reduction on platinum stepped surfaces in acidic media. J. Electroanal. Chem. 564, 141150 (2004).

79. Dong, Q., Santhanagopalan, S. \& White, R. E. Simulation of the Oxygen Reduction Reaction at an RDE in 0 . 5 M H 2 SO 4 Including an Adsorption Mechanism. 154, (2007).

80. Kuzume, A., Herrero, E. \& Feliu, J. M. Oxygen reduction on stepped platinum surfaces in acidic media. 599, 333-343 (2007).

81. Geniès, L., Faure, R. \& Durand, R. Electrochemical reduction of oxygen on platinum nanoparticles in alkaline media. Electrochim. Acta 44, 1317-1327 (1998).

82. Reyter, D., Chamoulaud, G., Bélanger, D. \& Roué, L. Electrocatalytic reduction of nitrate on copper electrodes prepared by high-energy ball milling. J. Electroanal. Chem. 596, 1324 (2006).

83. Mattarozzi, L. et al. Electrochemical reduction of nitrate and nitrite in alkaline media at CuNi alloy electrodes. Electrochim. Acta 89, 488-496 (2013).

84. Pentland, N., Bockris, J. O. \& Sheldon, E. Hydrogen Evolution Reaction on Copper, Gold, Molybdenum, Palladium, Rhodium, and Iron. J. Electrochem. Soc. 104, 182 (1957).

85. MathWorks. Symbolic Math Toolbox ${ }^{\text {TM }}$ User's Guide 2018a. 1714-1724 (2018).

86. Hirakawa, H., Hashimoto, M., Shiraishi, Y. \& Hirai, T. Photocatalytic Conversion of Nitrogen to Ammonia with Water on Surface Oxygen Vacancies of Titanium Dioxide. $J$. Am. Chem. Soc. 139, 10929-10936 (2017).

87. Suryanto, B. H. R. et al. Challenges and prospects in the catalysis of electroreduction of nitrogen to ammonia. Nat. Catal. 2, 290-296 (2019).

88. Sawyer, C. N., McCarty, P. L. \& Parkin, G. F. Chemistry for environmental engineering and science. (2003).

89. U.S. Environmental Protection Agency. 2018 Edition of the Drinking Water Standards and Health Advisories Tables. (2018).

90. U.S. EPA. Technical Development Document for the Effluent Limitations Guidelines and Standards for the Oil and Gas Extraction Point Source Category. United States Environmental Protection Agency vol. EPA-820-R- (2016).

91. U.S. Environmental Protection Agency \& US EPA. Development document for final effluent limitations guidelines and standards for the iron and steel manufacturing point source category. 1062 (2002).

92. U.S. Environmental Protection Agency. Industrial Wastewater Treatment Technologies Database.

93. Prasad, S., Weidner, J. W. \& Farell, A. E. A Boundary-Layer Model of A Parallel-Plate Electrochemical Reactor Model for the Destruction of Nitrate and Nitrite in Alkaline Waste Solutions. J. Electrochem. Soc. 142, 1152-1161 (1995).

94. Moreno, C., Farahbakhshazad, N. \& Morrison, G. M. Ammonia removal from oil refinery 
effluent in vertical upflow macrophyte column systems. Water. Air. Soil Pollut. 135, 237247 (2002).

95. Ghasemi, Z., Younesi, H. \& Zinatizadeh, A. A. Preparation, characterization and photocatalytic application of TiO2/Fe-ZSM-5 nanocomposite for the treatment of petroleum refinery wastewater: Optimization of process parameters by response surface methodology. Chemosphere 159, 552-564 (2016).

96. Abdel Wahaab, R. \& Alseroury, F. A. Wastewater treatment: a case study of electronics manufacturing industry. Int. J. Environ. Sci. Technol. 16, 47-58 (2019).

97. Hasebe, Y. et al. High-rate nitrification of electronic industry wastewater by using nitrifying granules. Water Sci. Technol. 76, 3171-3180 (2017).

98. Garcia-Rodriguez, O. et al. Mineralization of electronic wastewater by electro-Fenton with an enhanced graphene-based gas diffusion cathode. Electrochim. Acta 276, 12-20 (2018).

99. Mousset, E., Wang, Z., Olvera-Vargas, H. \& Lefebvre, O. Advanced electrocatalytic pretreatment to improve the biodegradability of real wastewater from the electronics industry - A detailed investigation study. J. Hazard. Mater. 360, 552-559 (2018).

100. Shivaraman, N. et al. A two-stage biological treatment system for ammonium-nitrateladen wastewater. World J. Microbiol. Biotechnol. 17, 447-453 (2001).

101. Maine, M. A. et al. Hybrid constructed wetlands for the treatment of wastewater from a fertilizer manufacturing plant: Microcosms and field scale experiments. Sci. Total Environ. 650, 297-302 (2019).

102. Jianping, W., Xiaoqiang, J., Lei, P., Changlin, W. \& Guozhu, M. Nitrifying treatment of wastewater from fertilizer production in a multiple airlift loop bioreactor. Biochem. Eng. J. 25, 33-37 (2005).

103. Jianping, W., Wei, P. L. H., Liping, D. \& Guozhu, M. The denitrification of nitrate contained wastewater in a gas-liquid-solid three-phase flow airlift loop bioreactor. Biochem. Eng. J. 15, 153-157 (2003).

104. Akyol, A., Can, O. T., Demirbas, E. \& Kobya, M. A comparative study of electrocoagulation and electro-Fenton for treatment of wastewater from liquid organic fertilizer plant. Sep. Purif. Technol. 112, 11-19 (2013).

105. Gabaldon, C. et al. Biological nitrate removal from wastewater of a metal-finishing industry. 148, 485-490 (2007).

106. Bockris, J. O. Electrochemical Reductions of $\mathrm{Hg}(\mathrm{II})$, Ruthenium-Nitrosyl Complex, Chromate, and Nitrate in a Strong Alkaline Solution. J. Electrochem. Soc. 143, 3801 (1996). 


\section{Electronic Supplementary Information}

\section{Harnessing Photoelectrochemistry for Wastewater Nitrate Treatment Coupled with Resource Recovery}

Luisa Barrera ${ }^{1}$ and Rohini Bala Chandran ${ }^{1 *}$

${ }^{1}$ Department of Mechanical Engineering, 2350 Hayward St., G. G. Brown Building, University of Michigan, Ann Arbor, MI 48109

\footnotetext{
* Corresponding author: rbchan@umich.edu
} 


\section{Nomenclature}

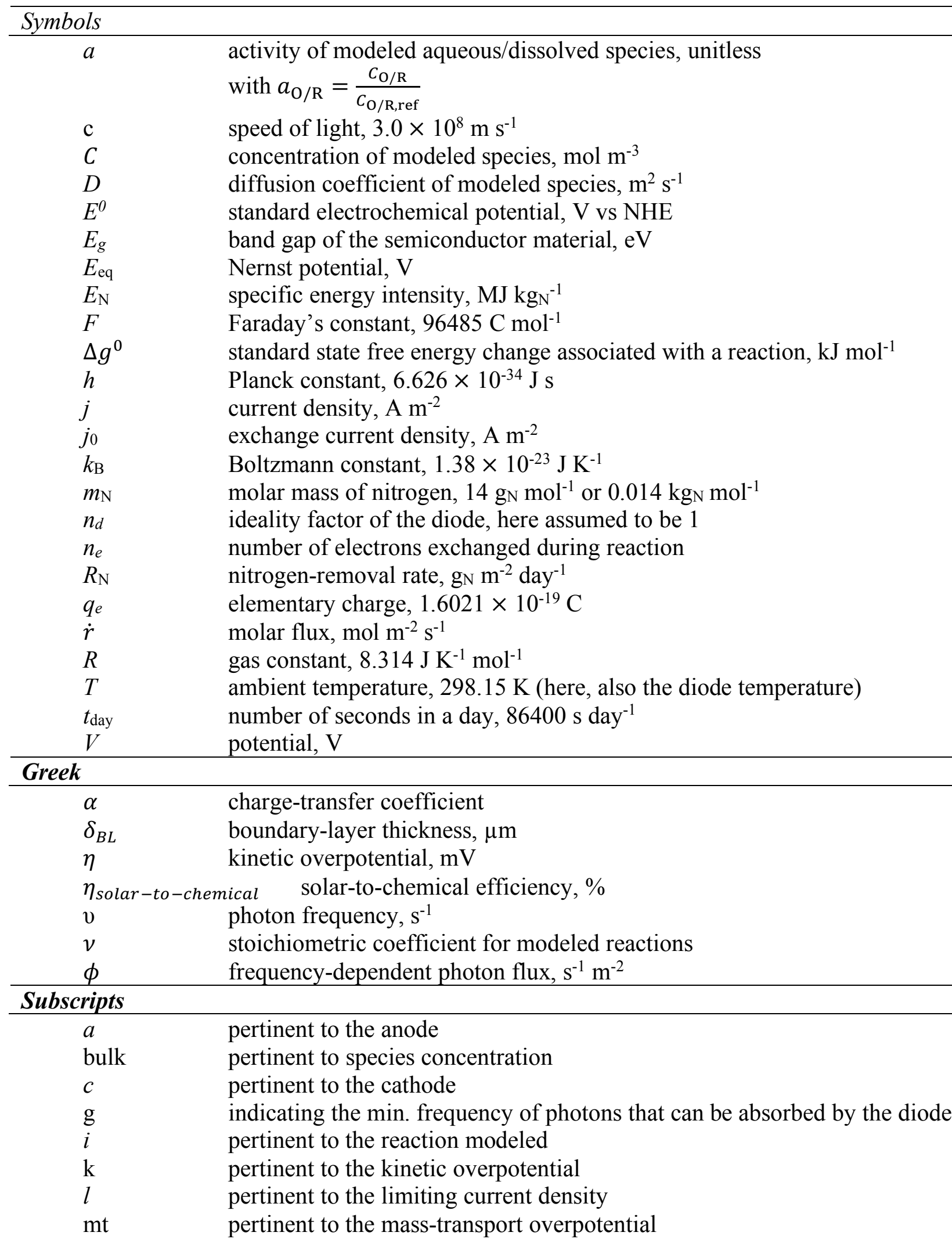




\begin{tabular}{ll} 
O & pertinent to the oxidized species \\
op & pertinent to the operating current density and potential of the device \\
R & pertinent to the reduced species \\
ref & pertinent to the reference value from the literature \\
rr & pertinent to the radiation recombination current density \\
sc & pertinent to the short-circuit current density \\
solar & pertinent to the incident solar spectrum \\
tot & total \\
\hline Other & \\
\hline AM1.5 & air mass 1.5 reference spectrum for terrestrial solar insolation \\
BOD & biological oxygen demand, mg-O $2 /$ L \\
$\mathrm{e}^{-} / h^{+}$ & electron/hole pair \\
EPA & U.S. Environmental Protection Agency \\
HER & hydrogen evolution reaction \\
NO3RR & nitrate reduction reaction \\
OER & oxygen evolution reaction \\
ORR & oxygen reduction reaction \\
R1 & net reaction 1, where nitrates are converted to ammonia \\
R2 & net reaction 2, where nitrates are converted to nitrous oxide \\
R3 & net reaction 3, where nitrates are converted to nitrogen \\
RE & relative difference \\
RHE & reversible hydrogen electrode, used as a reference \\
$\sim$ & on the same order of magnitude
\end{tabular}




\section{Solar-to-Chemical Efficiencies and Nitrogen Removal/Recovery Rates}

Figure S1 shows the relative difference (RE) for the solar-to-chemical efficiency was calculated by comparing the efficiencies with, $\eta_{\text {solar-to-chemical,comp }}$, and without, $\eta_{\text {solar-to-chemical,no comp, }}$, competing reactions as function of the bulk $\mathrm{NO}_{3}{ }^{-}$concentration. Both HER and ORR were implemented with "worst-case" kinetic parameters. An increase in this relative difference corresponds to an increase in the effect of the competing reactions; a value of $100 \%$ implies that the efficiency value with competing reactions approached 0 . On Figure S1(a), the relative difference decreases with increasing concentration for all band gaps, with the largest values overall reached by $\mathrm{TiO}_{2}$ and $\mathrm{Si}$. For the formation of $\mathrm{N}_{2} \mathrm{O}$, on Figure 1(b), the smaller concentrations show less of an effect due to the competing reactions, which follows from the mass-transport limited behavior of the NO3RR shown on Figure 6.

$$
R E(\%)=\frac{\eta_{\text {solar-to-chemical,no comp }}-\eta_{\text {solar-to-chemical,comp }}}{\eta_{\text {solar-to-chemical,no comp }}}
$$

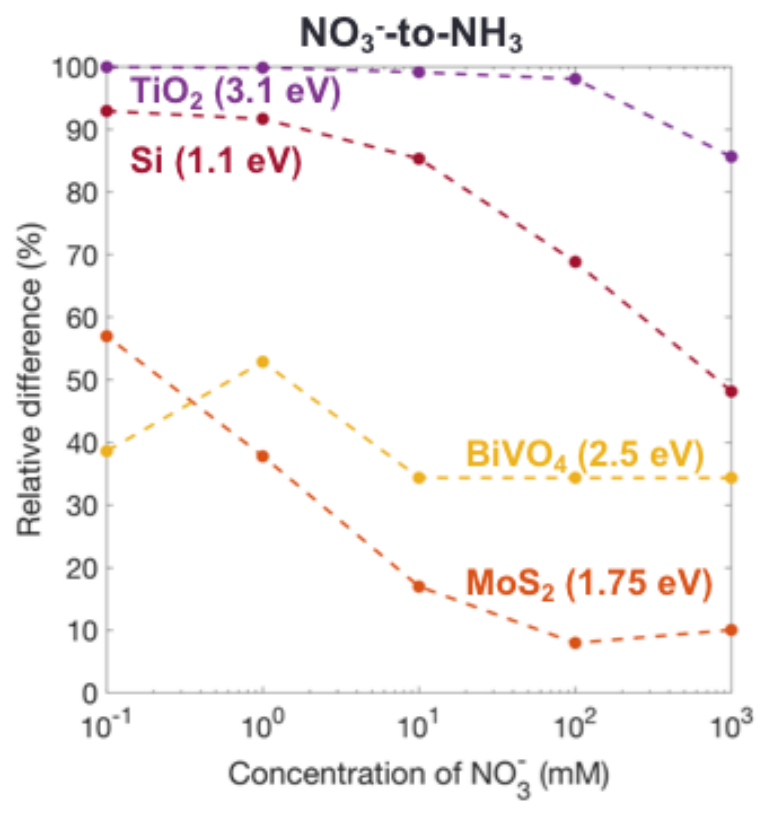

(a)

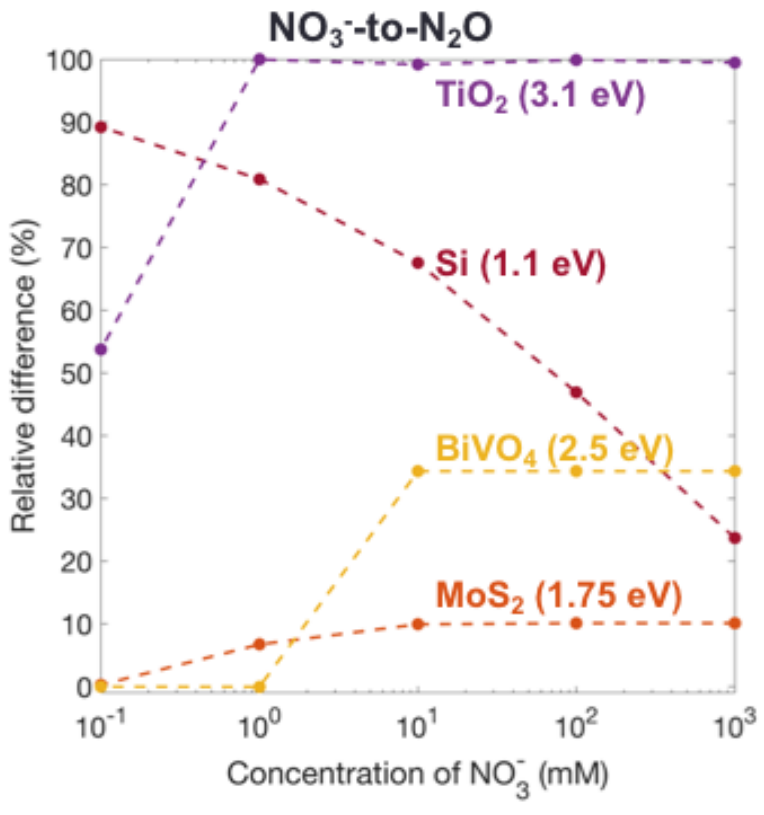

(b)

Figure S1: Relative decrease (\%) as a function of $\mathrm{NO}_{3}{ }^{-}$concentration for $\mathrm{Si}$ (red), $\mathrm{MoS}_{2}$ (orange), $\mathrm{BiVO}_{4}$ (yellow) and $\mathrm{TiO}_{2}$ (purple) as discussed in Figure 6 for the (a) $\mathrm{NO}_{3}{ }^{-}$-to- $\mathrm{NH}_{3}$ transformation and (b) $\mathrm{NO}_{3}{ }^{-}$-to- $\mathrm{N}_{2} \mathrm{O}$ transformation 


\section{Comparison with state-of-the-art nitrogen-removal technologies}

The ammonia stripping reactor recovers $\mathrm{NH}_{3} / \mathrm{NH}_{4}{ }^{+}$nutrients that are present in the solution in an electrochemical flow cell by applying an electric field ${ }^{1}$. This approach offers the advantages of high nitrogen-recovery rates, up to $384 \mathrm{~g}_{\mathrm{N}} \mathrm{m}^{-2}$ day $^{-1}$, because of improved mass-transport in flow reactors ${ }^{1}$. However, it relies on the presence of $\mathrm{NH}_{3} / \mathrm{NH}_{4}{ }^{+}$in the waste stream, unlike our device that transforms the $\mathrm{NO}_{3}$ - to $\mathrm{NH}_{3}$ or $\mathrm{N}_{2} \mathrm{O}$ already.

The Sharon-Anammox process is an energy-efficient, biological pathway to transform reactive-nitrogen contaminants present in the form of $\mathrm{NH}_{3} / \mathrm{NH}_{4}^{+}$to $\mathrm{N}_{2}{ }^{2}$. However, with this approach the nutrients in wastewater are not recovered but lost as $\mathrm{N}_{2}$. Because this process is typically carried out in batch-reactors, volumetric nitrogen-removal rates of up to $2 \mathrm{kgN} \mathrm{m}^{-3}$ day $^{-1}$ have been reported ${ }^{3,4}$. To translate the volumetric rate to an aerial rate, a biofilm $/ \mathrm{membrane}$ specific surface area of $\sim 200 \mathrm{~m}^{-2} \mathrm{~m}^{-3}$ was assumed ${ }^{5}$, which results in an areal rate of approximately $10 \mathrm{~g}_{\mathrm{N}} \mathrm{m}^{-2}$ day $^{-1}$.

\section{References:}

1. Kuntke, P. et al. (Bio) electrochemical ammonia recovery : progress and perspectives. Appl. Microbiol. Biotechnol. 2, 3865-3878 (2018).

2. Dongen, L. G. J. . van, Jetten, M. S. M. \& Loosdrecht, M. C. M. van. The Combined Sharon/Anammox Process: A sustainable method for N-removal from sludge water. (2001).

3. Lackner, S. et al. Full-scale partial nitritation/anammox experiences - An application survey. Water Res. 55, 292-303 (2014).

4. Maurer, M., Schwegler, P. \& Larsen, T. A. Nutrients in urine: Energetic aspects of removal and recovery. Water Sci. Technol. 48, 37-46 (2003).

5. Xie, G. J., Cai, C., Hu, S. \& Yuan, Z. Complete nitrogen removal from synthetic anaerobic sludge digestion liquor through integrating anammox and denitrifying anaerobic methane oxidation in a membrane biofilm reactor. Environ. Sci. Technol. 51, 819-827 (2017). 